\title{
System Characterization Report on the WorldView-3 Imager
}

\author{
Chapter I of
}

System Characterization of Earth Observation Sensors

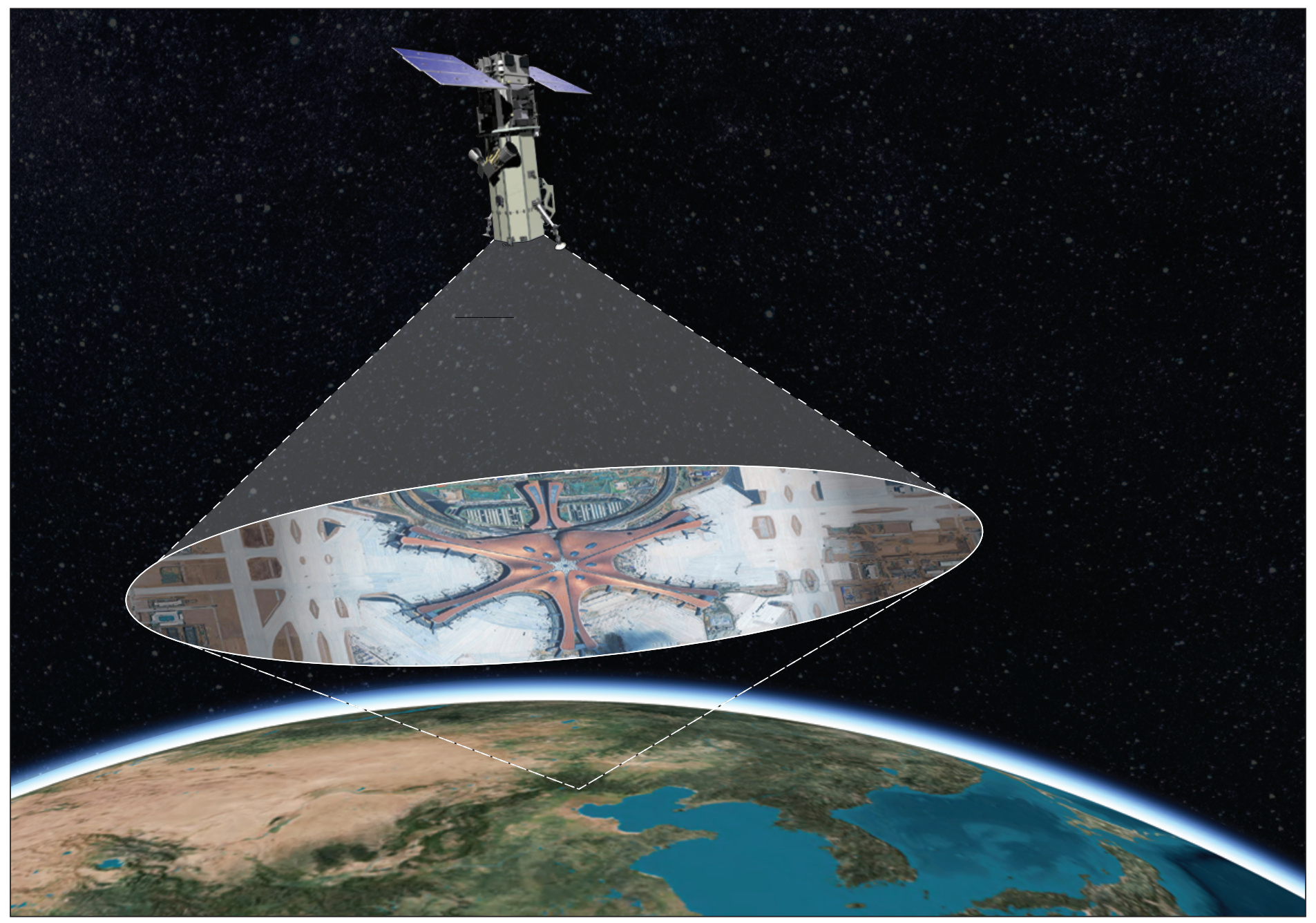

Open-File Report 2021-1030-I

Version 1.1, October 2021

U.S. Department of the Interior

U.S. Geological Survey 
Cover: Artistic rendering of WorldView-3 in orbit. Image courtesy of Maxar Technologies, 2019, used with permission. WorldView-3 image of Beijing Daxing International Airport, Beijing, China. Image courtesy of Maxar Technologies, 2019, used with permission. Image of Asia from Analytical Graphics, Inc., Systems Tool Kit. 


\section{System Characterization Report on the WorldView-3 Imager}

By Simon J. Cantrell, ${ }^{1}$ Jon B. Christopherson, ${ }^{1}$ Cody Anderson, ${ }^{2}$ Gregory L.

Stensaas, ${ }^{2}$ Shankar N. Ramaseri Chandra, ${ }^{1}$ Minsu Kim, ${ }^{1}$ and Seonkyung Park ${ }^{1}$

Chapter I of

System Characterization of Earth Observation Sensors

Compiled by Shankar N. Ramaseri Chandra ${ }^{1}$

${ }^{1}$ KBR, Inc., under contract to the U.S. Geological Survey.

${ }^{2}$ U.S. Geological Survey.

Open-File Report 2021-1030-I

Version 1.1, October 2021 


\section{U.S. Geological Survey, Reston, Virginia: 2021 \\ First release: 2021 \\ Revised: October 2021 (ver 1.1)}

For more information on the USGS - the Federal source for science about the Earth, its natural and living resources, natural hazards, and the environment—visit https://www.usgs.gov or call 1-888-ASK-USGS.

For an overview of USGS information products, including maps, imagery, and publications, visit https://store.usgs.gov/.

Any use of trade, firm, or product names is for descriptive purposes only and does not imply endorsement by the U.S. Government.

Although this information product, for the most part, is in the public domain, it also may contain copyrighted materials as noted in the text. Permission to reproduce copyrighted items must be secured from the copyright owner.

Suggested citation:

Cantrell, S.J., Christopherson, J.B., Anderson, C., Stensaas, G.L., Ramaseri Chandra, S.N., Kim, M., and Park, S., 2021, System characterization report on the WorldView-3 Imager (ver. 1.1, October 2021), chap. I of Ramaseri Chandra, S.N., comp., System characterization of Earth observation sensors: U.S. Geological Survey Open-File Report 2021-1030, 29 p., https://doi.org/10.3133/ofr20211030l.

ISSN 2331-1258 (online) 


\section{Contents}

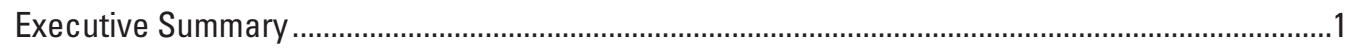

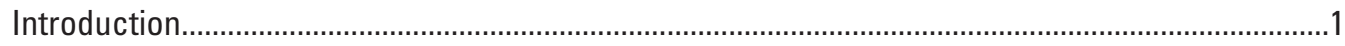

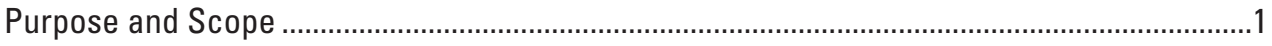

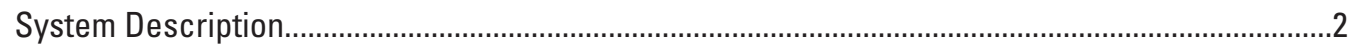

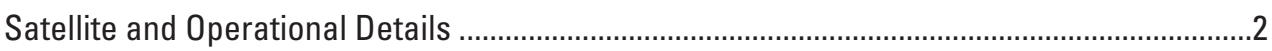

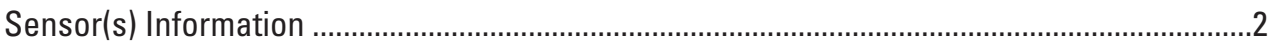

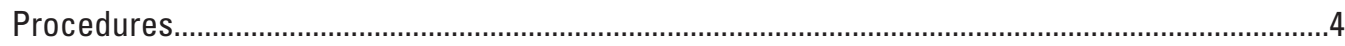

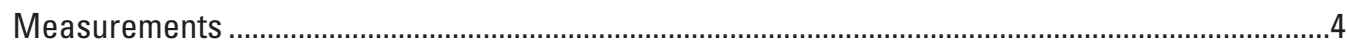

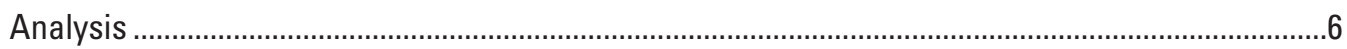

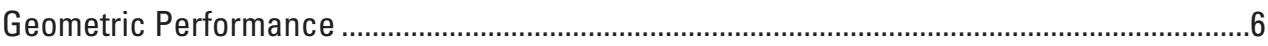

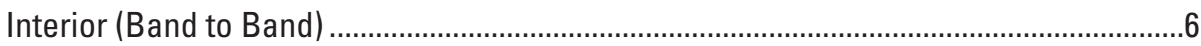

Exterior (Geometric Location Accuracy) ........................................................................

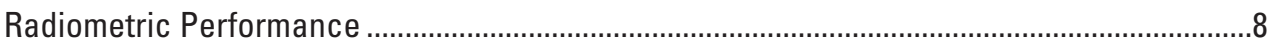

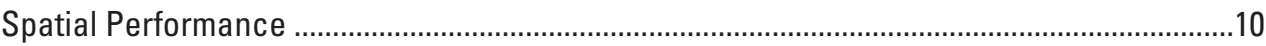

Summary and Conclusions......................................................................................................

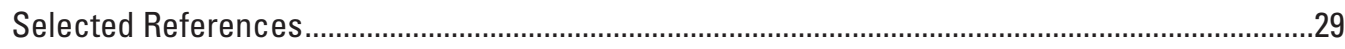

\section{Figures}

1. Graph showing WorldView-3 visible and near-infrared relative spectral response.........3

2. Graph showing WorldView-3 shortwave infrared relative spectral response ..................4

3. Band 2 (blue) to band 3 (green) geometric error map of Boulder, Colorado ......................7

4. Band 2 (blue) to band 3 (green) geometric error histogram for Boulder, Colorado...........7

5. Band 3 (green) to band 4 (yellow) geometric error map of Boulder, Colorado ..................8

6. Band 3 (green) to band 4 (yellow) geometric error histogram for Boulder, Colorado.......8

7. Band 7 (near infrared 1) to band 8 (near infrared 2) geometric error map of

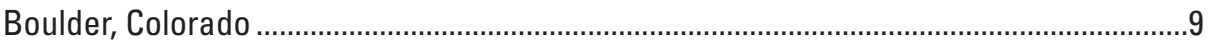

8. Band 7 (near infrared 1) to band 8 (near infrared 2) geometric error histogram for Boulder, Colorado ..............................................................................................

9. Shortwave infrared 2 to shortwave infrared 3 geometric error map of Longmont, Colorado ................................................................................................. 10

10. Shortwave infrared 2 to shortwave infrared 3 geometric easting error histogram for Longmont, Colorado ..............................................................................11

11. Shortwave infrared 2 to shortwave infrared 3 geometric northing error histogram for Longmont, Colorado .............................................................................11

12. Shortwave infrared 5 to shortwave infrared 6 geometric error map of Longmont,

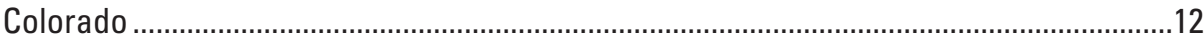

13. Shortwave infrared 5 to shortwave infrared 6 geometric easting error histogram for Longmont, Colorado

14. Shortwave infrared 5 to shortwave infrared 6 geometric northing error histogram for Longmont, Colorado

15. Shortwave infrared 6 to shortwave infrared 7 geometric error map of Longmont, Colorado. 
16. Shortwave infrared 6 to shortwave infrared 7 geometric easting error histogram for Longmont, Colorado

17. Shortwave infrared 6 to shortwave infrared 7 geometric northing error histogram for Longmont, Colorado

18. Relative geometric error comparison for Sentinel-2 and WorldView-3 for near infrared, Boulder, Colorado

19. Relative geometric easting error histogram comparison for Sentinel-2 and WorldView-3 for near infrared, Boulder, Colorado .

20. Relative geometric northing error histogram comparison for Sentinel-2 and WorldView-3 for near infrared, Boulder, Colorado ...

21. Relative geometric error comparison for Sentinel-2 and WorldView-3 for near infrared, Fort Lupton, Colorado.

22. Relative geometric easting error histogram comparison for Sentinel-2 and WorldView-3 for near infrared, Fort Lupton, Colorado 19

23. Relative geometric northing error histogram comparison for Sentinel-2 and WorldView-3 for near infrared, Fort Lupton, Colorado 19

24. Relative geometric error comparison for Sentinel-2 and WorldView-3 for near infrared, Longmont, Colorado...

25. Relative geometric easting error histogram comparison for Sentinel-2 and WorldView-3 for near infrared, Longmont, Colorado.

26. Relative geometric northing error histogram comparison for Sentinel-2 and WorldView-3 for near infrared, Longmont, Colorado.

27. Relative geometric error comparison for Sentinel-2 and WorldView-3 for shortwave infrared, Longmont, Colorado

28. Relative geometric easting error histogram comparison for Sentinel-2 and WorldView-3 for shortwave infrared, Longmont, Colorado.

29. Relative geometric northing error histogram comparison for Sentinel-2 and WorldView-3 for shortwave infrared, Longmont, Colorado.

30. Top of Atmosphere reflectance comparison for WorldView-3 and Sentinel-2 for blue, green, red, and near-infrared bands for Boulder, Colorado

31. Top of Atmosphere reflectance comparison for WorldView-3 and Sentinel-2 for blue, green, red, and near-infrared bands for Fort Lupton, Colorado.

32. Top of Atmosphere reflectance comparison for WorldView-3 and Sentinel-2 for blue, green, red, and near-infrared bands for Longmont, Colorado

33. Top of Atmosphere reflectance comparison for WorldView-3 and Sentinel-2 for shortwave infrared 3 and shortwave infrared 7 for Longmont, Colorado ........................25

34. Graphs showing band 2 (blue) edge spread and line spread functions...........................26

35. Graphs showing band 3 (green) edge spread and line spread functions ........................27

36. Graphs showing band 5 (red) edge spread and line spread functions ..........................27

37. Graphs showing band 7 (near infrared 1) edge spread and line spread functions.........28

\section{Tables}

1. Satellite and operational details for WorldView-3

2. Imaging sensor details for WorldView-3 ……...........................................................

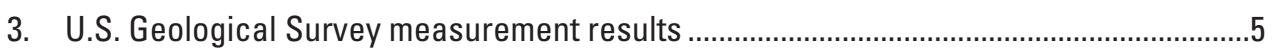

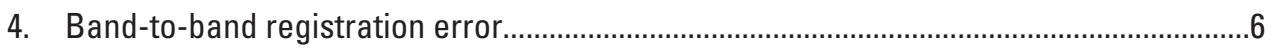




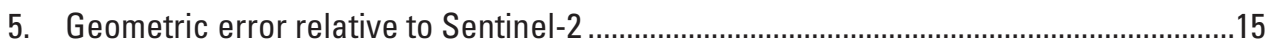

6. Top of Atmosphere reflectance comparison of WorldView-3 images against

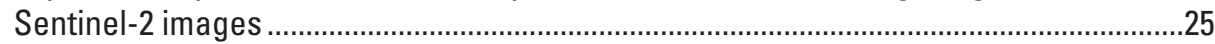

7. Top of Atmosphere reflectance comparison of WorldView-3 images against

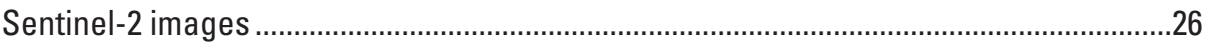

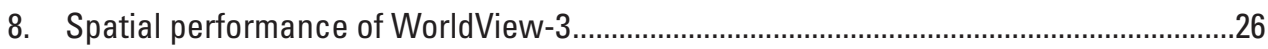

\section{Conversion Factors}

International System of Units to U.S. customary units

\begin{tabular}{lll}
\hline \multicolumn{1}{c}{ Multiply } & By & \multicolumn{1}{c}{ To obtain } \\
\hline centimeter $(\mathrm{cm})$ & Length & \\
meter $(\mathrm{m})$ & 0.3937 & inch (in.) \\
meter $(\mathrm{m})$ & 3.281 & foot (ft) \\
kilometer $(\mathrm{km})$ & 1.094 & yard (yd) \\
\hline
\end{tabular}

\section{Abbreviations}

$\begin{array}{ll}\text { ECCOE } & \text { EROS Cal/Val Center of Excellence } \\ \text { EROS } & \text { Earth Resources Observation and Science } \\ \text { GSD } & \text { ground sample distance } \\ \text { JACIE } & \text { Joint Agency Commercial Imagery Evaluation } \\ \text { NIR } & \text { near infrared } \\ \text { SWIR } & \text { shortwave infrared } \\ \text { USGS } & \text { U.S. Geological Survey } \\ \text { VNIR } & \text { visible and near infrared }\end{array}$





\title{
System Characterization Report on the WorldView-3 Imager
}

\author{
By Simon J. Cantrell, ${ }^{1}$ Jon B. Christopherson, ${ }^{1}$ Cody Anderson, ${ }^{2}$ Gregory L. Stensaas, ${ }^{2}$ Shankar N. Ramaseri \\ Chandra, ${ }^{1}$ Minsu Kim, ${ }^{1}$ and Seonkyung Park ${ }^{1}$
}

\section{Executive Summary}

This report addresses system characterization of the Maxar WorldView-3 satellite and is part of a series of system characterization reports produced and delivered by the U.S. Geological Survey Earth Resources Observation and Science Cal/Val Center of Excellence in 2020. These reports present and detail the methodology and procedures for characterization; present technical and operational information about the specific sensing system being evaluated; and provide a summary of test measurements, data retention practices, data analysis results, and conclusions.

WorldView-3 is a high-resolution multispectral satellite launched in 2014 by Maxar Technologies on an Atlas V launch vehicle from Vandenberg Air Force Base in California for Earth resources monitoring. WorldView-3 provides substantial technical improvements to previous WorldView satellites, including spectral bands, ground sample distance, and swath. The WorldView-3 satellite was designed and built by Lockheed Martin for Maxar Technologies using the BCP-5000 bus with the WorldView-3 Imager and the Clouds, Aerosols, Vapors, Ice, and Snow sensor. The high-resolution WorldView-3 Imager is the main instrument, and the Clouds, Aerosols, Vapors, Ice, and Snow sensor provides additional data on obscurants and other atmospheric effects used in data production. More information on Maxar WorldView satellites and sensors is available within the "2020 Joint Agency Commercial Imagery Evaluation-Remote Sensing Satellite Compendium" and from the manufacturer at https://www. maxar.com/.

The Earth Resources Observation and Science Cal/Val Center of Excellence system characterization team completed data analyses to characterize the geometric (interior and exterior), radiometric, and spatial performances. Results of these analyses indicate that WorldView-3 has a range of interior geometric performance of -0.09 ( -0.07 pixel) to 0.24 meter ( 0.19 pixel) in band-to-band registration; an exterior geometric performance in the range of a $-21.10-(-2.11$ pixels $)$ to 28.23-meter (2.82 pixels) offset in comparison to Sentinel-2;

\footnotetext{
${ }^{1}$ KBR, Inc., under contract to the U.S. Geological Survey.

${ }^{2}$ U.S. Geological Survey.
}

a radiometric performance in the range of -0.121 to 1.420 (offset and slope); and a spatial performance in the range of 1.2 to 1.7 pixels at full width at half maximum with a modulation transfer function at a Nyquist frequency in the range of 0.093 to 0.185 .

\section{Introduction}

The imaging sensor onboard WorldView-3 was built by ITT Exelis. The WorldView-3 Imager provides the same eight visible and near-infrared (VNIR) bands as WorldView-2 and adds eight shortwave infrared (SWIR) bands. The ground sample distance (GSD) is improved to 31 centimeters for panchromatic data, 1.2 meters $(\mathrm{m})$ in VNIR, and $3.7 \mathrm{~m}$ in SWIR; however, terms of its licensing as of 2018 require Maxar Technologies to resample the SWIR data to a $7.5-\mathrm{m}$ effective GSD. Maxar Technologies is working with the U.S. Government to revise this restriction so that SWIR data can be distributed at their 3.7-m native resolution.

The data analysis results provided within this report have been derived from approved Joint Agency Commercial Imagery Evaluation (JACIE) processes and procedures. JACIE was formed to leverage resources from several Federal agencies for the characterization of remote sensing data and to share those results across the remote sensing community. More information about JACIE is available at https://www.usgs.gov/ core-science-systems/eros/calval/jacie?qt-science_support page_related_con=3\#qt-science_support_page_related_con.

\section{Purpose and Scope}

The purpose of this report is to describe the specific sensor or sensing system, test its performance in three categories, complete related data analyses to quantify these performances, and report the results in a standardized document. In this chapter, the WorldView-3 sensor is described. The performance of the system is limited to geometric, radiometric, and spatial. The scope of the geometric assessment is limited to testing the interior alignments of spectral bands against each other, and the exterior alignment is tested in reference to Sentinel-2. 
The U.S. Geological Survey (USGS) Earth Resources Observation and Science (EROS) Cal/Val Center of Excellence (ECCOE) project, and the associated system characterization process used for this assessment, follows the USGS Fundamental Science Practices, which include maintaining data, information, and documentation needed to reproduce and validate the scientific analysis documented in this report. Additional information and guidance about Fundamental Science Practices and related resource information of interest to the public are available at https:/www .usgs.gov/about/organization/science-support/office-sciencequality-and-integrity/fundamental-science-practices. For additional information related to this report, please contact the ECCOE at eccoe@usgs.gov.

Table 1. Satellite and operational details for WorldView-3.

\section{System Description}

This section describes the satellite and operational details and provides information about the WorldView-3 sensor.

\section{Satellite and Operational Details}

The satellite and operational details for WorldView-3 are listed in table 1.

\section{Sensor(s) Information}

The imaging sensor details for WorldView-3 are listed in table 2. The relative spectral responses for WorldView-3 VNIR and SWIR are shown in figures 1 and 2, respectively.

[kg, kilogram; m, meter; kW, kilowatt; Ahr, ampere hour; ${ }^{\circ}$, degree; min, minute; VNIR, visible and near infrared; SWIR, shortwave infrared]

\begin{tabular}{|c|c|}
\hline Product information & WorldView-3 data \\
\hline \multicolumn{2}{|r|}{ Satellite and operational information } \\
\hline Product name & Top of Atmosphere reflectance \\
\hline Sensor name(s) & WorldView-3 Imager \\
\hline Lift-off mass & $2,800 \mathrm{~kg}$ \\
\hline Sensor type & Multispectral, visible, and infrared \\
\hline Platform owner & Maxar Technologies \\
\hline Power & 3.1-kW solar array, 100-Ahr battery \\
\hline Mission type & Global land-monitoring tasking mission \\
\hline Launch date & August 13, 2014 \\
\hline Operating orbit & Sun-synchronous \\
\hline Orbital altitude range & $620 \mathrm{~km}$ \\
\hline Sensor angle altitude & $97.9^{\circ}$ inclination \\
\hline Altitude and orbit control & 3-axis stabilized \\
\hline Orbit period & $96.98 \mathrm{~min}$ \\
\hline Imaging time & 10:30 descending node \\
\hline Temporal resolution & 5 days at $20^{\circ}$ off nadir or less \\
\hline Temporal coverage & 2014 to present \\
\hline
\end{tabular}


Table 2. Imaging sensor details for WorldView-3.

[ $\mu \mathrm{m}$, micrometer; m, meter; NIR, near infrared; SWIR, shortwave infrared]

\begin{tabular}{|c|c|c|c|c|}
\hline \multirow[b]{2}{*}{ Spectral band(s) details } & \multicolumn{4}{|c|}{ WorldView-3 } \\
\hline & $\begin{array}{l}\text { Lower band } \\
\qquad(\mu \mathrm{m})\end{array}$ & $\begin{array}{l}\text { Upper band } \\
(\mu \mathrm{m})\end{array}$ & $\begin{array}{l}\text { Radiometric resolution } \\
\text { (bits) }\end{array}$ & $\begin{array}{l}\text { Ground sample distance } \\
(\mathrm{m})\end{array}$ \\
\hline Band 1-Coastal aerosol & 0.440 & 0.450 & 11 & 1.24 \\
\hline Band 2-Blue & 0.450 & 0.510 & 11 & 1.24 \\
\hline Band 3-Green & 0.510 & 0.580 & 11 & 1.24 \\
\hline Band 4-Yellow & 0.585 & 0.625 & 11 & 1.24 \\
\hline Band 5-Red & 0.630 & 0.690 & 11 & 1.24 \\
\hline Band 6-Red edge & 0.705 & 0.745 & 11 & 1.24 \\
\hline Band 7-NIR 1 & 0.770 & 0.895 & 11 & 1.24 \\
\hline Band 8-NIR 2 & 0.860 & 1.040 & 11 & 1.24 \\
\hline Band 9-Panchromatic & 0.450 & 0.800 & 11 & 0.31 \\
\hline SWIR 1 & 1.550 & 1.590 & 14 & 3.7 \\
\hline SWIR 2 & 1.640 & 1.680 & 14 & 3.7 \\
\hline SWIR 3 & 1.710 & 1.750 & 14 & 3.7 \\
\hline SWIR 4 & 2.145 & 2.185 & 14 & 3.7 \\
\hline SWIR 5 & 2.185 & 2.225 & 14 & 3.7 \\
\hline SWIR 6 & 2.235 & 2.285 & 14 & 3.7 \\
\hline SWIR 7 & 2.295 & 2.365 & 14 & 3.7 \\
\hline
\end{tabular}

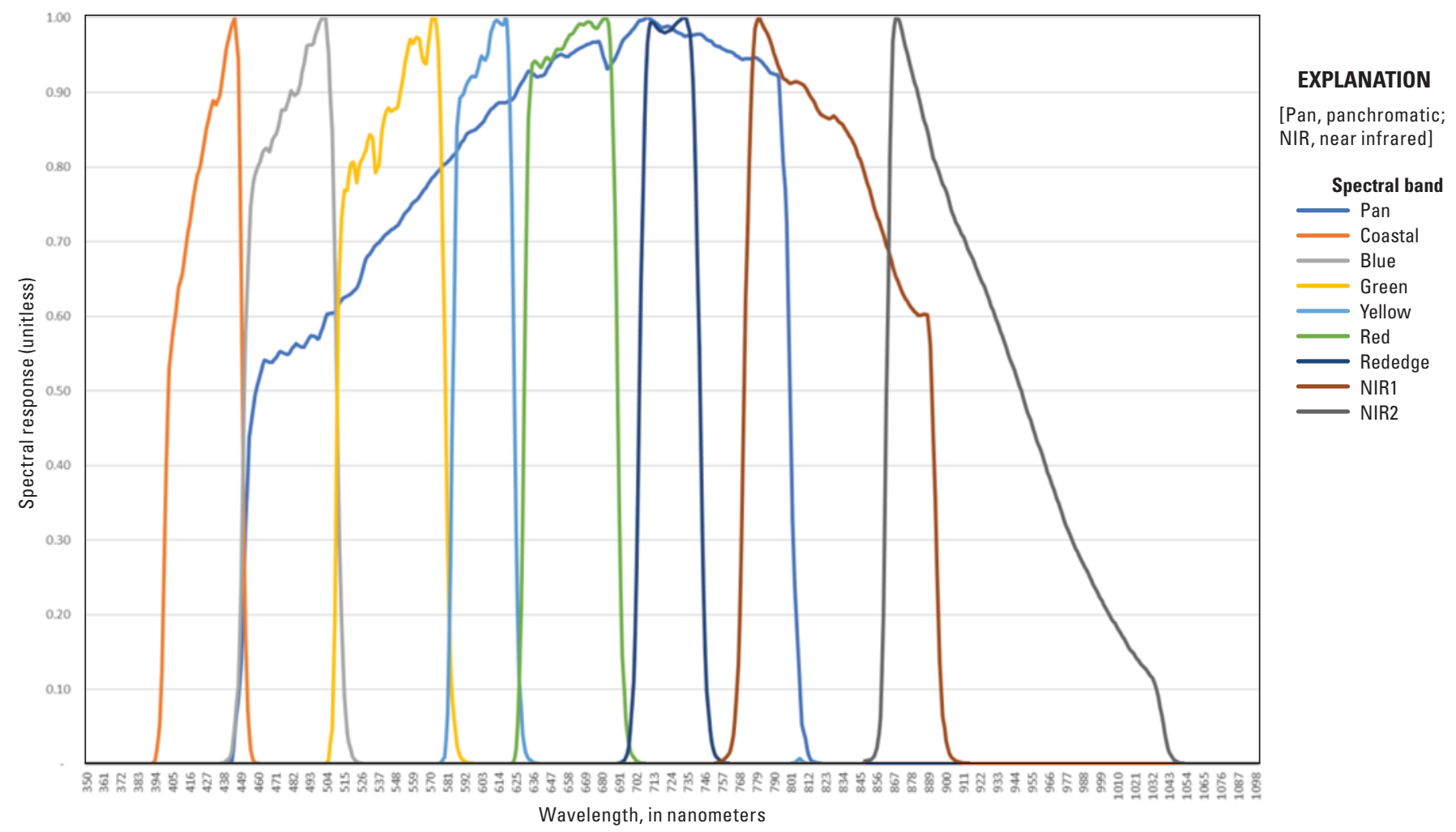

Figure 1. WorldView-3 visible and near-infrared relative spectral response. 


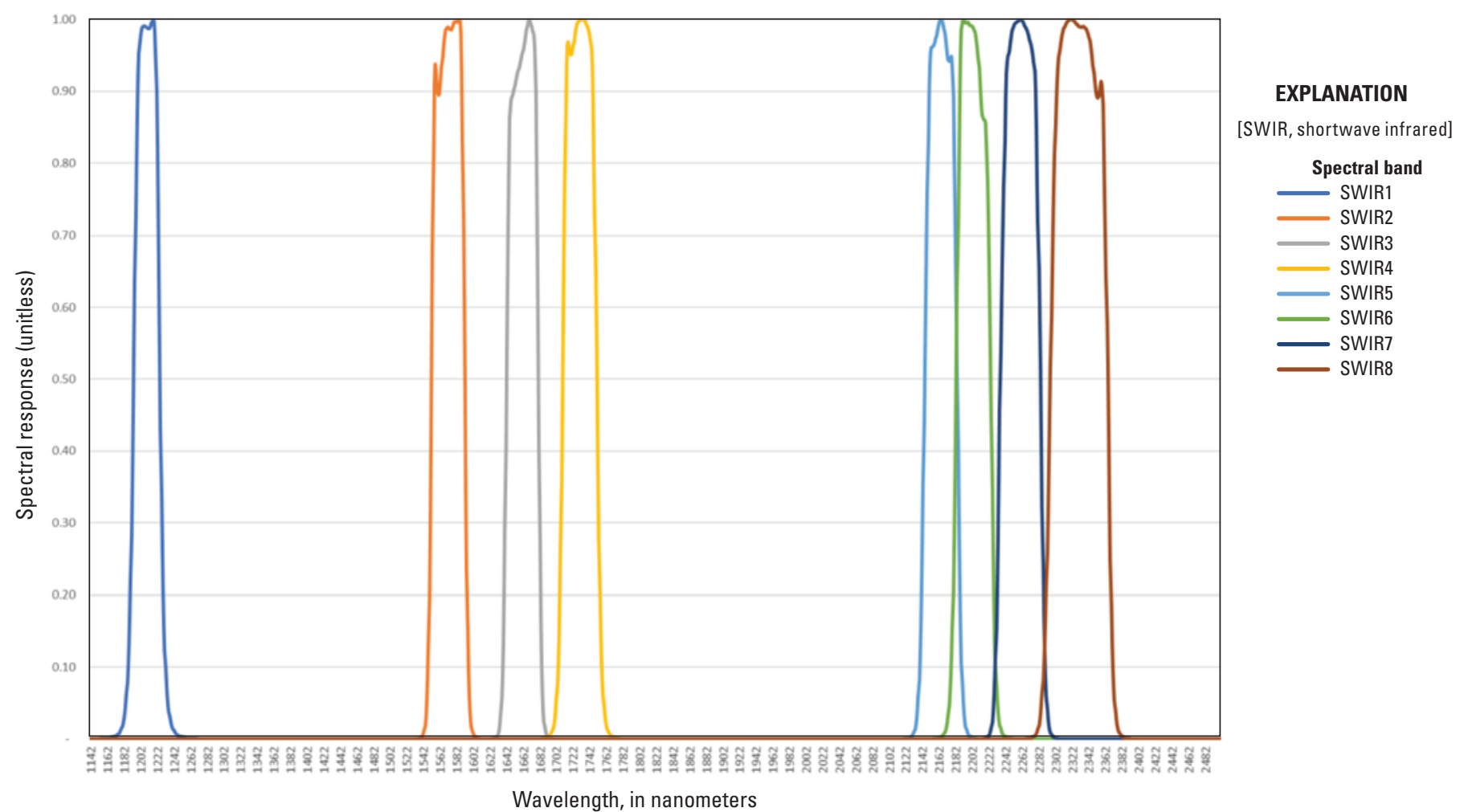

Figure 2. WorldView-3 shortwave infrared relative spectral response.

\section{Procedures}

ECCOE has established standard processes to identify Earth observing systems of interest and to assess the geometric, radiometric, and spatial qualities of data products from these systems.

The assessment steps are as follows:

- system identification and investigation to learn the general specifications of the satellite and its sensor(s);

- data receipt and initial inspection to understand the characteristics and any overt flaws in the data product so that it may be further analyzed;

- geometry characterization, including interior geometric orientation measuring the relative alignment of spectral bands and exterior geometric orientation measuring how well the georeferenced pixels within the image are aligned to a known reference;
- radiometry characterization, including assessing how well the data products correlate with a known reference and, when possible, assessing the signal-to-noise ratio; and

- spatial characterization, assessing the two-dimensional fidelity of the image pixels to their projected GSD.

Data analysis and test results are maintained at the USGS EROS Center by the ECCOE project.

\section{Measurements}

The observed USGS measurements are listed in table 3. Physical error, in meters, is calculated by the GSD (1.24-m VNIR band to band, 3.7-m SWIR band to band, 10.0-m VNIR image to image, and 20.0-m SWIR image to image) multiplied by the pixel error. Details about the methodologies used are outlined in the "Analysis" section. 
Table 3. U.S. Geological Survey measurement results.

[USGS, U.S. Geological Survey; STD, standard deviation; m, meter; NIR, near infrared; SWIR, shortwave infrared; FWHM, full width at half maximum; MTF, modulation transfer function]

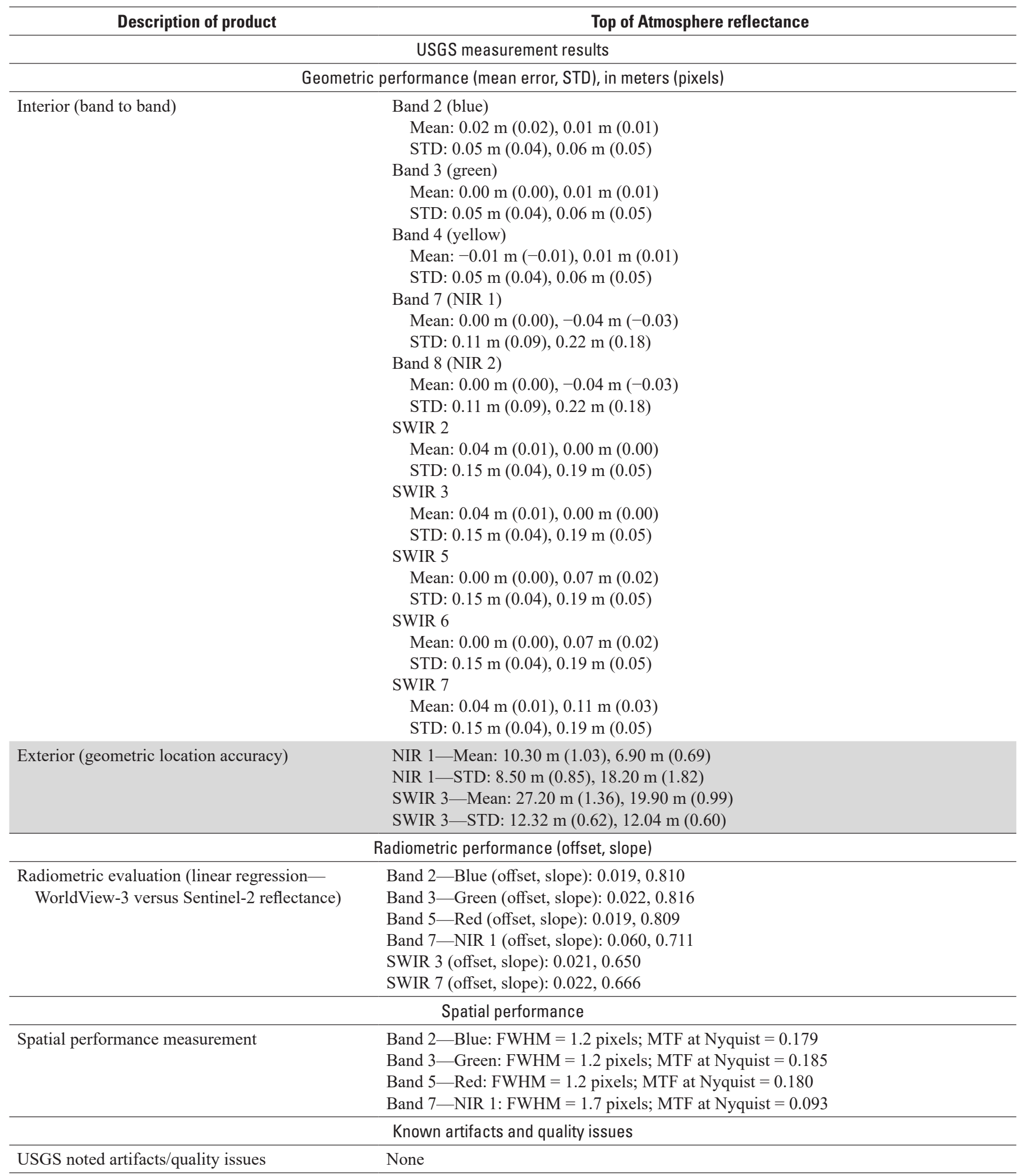




\section{Analysis}

This section of the report describes the geometric, radiometric, and spatial performance of WorldView-3.

\section{Geometric Performance}

The geometric performance for WorldView-3 are characterized in terms of the interior (band-to-band alignment) and exterior (geometric location accuracy) geometric analysis results.

\section{Interior (Band to Band)}

The interior or band-to-band alignment analysis was completed on three separate images over the United States: Boulder image (Colorado; scene identifier 20MAY26181014-M1BS-013079068010_01 P002), Fort Lupton image (Colorado; scene identifier
19MAY02182702-M1BS-013136294010_01_P001), and Longmont image (Colorado; scene identifier 18AUG10180726-M1BS-013107057010 01 P002). Band combinations were registered against each other to determine the mean error and standard deviation, as listed in table 4, with results represented in pixels and meters at 1.24-m VNIR and 3.7-m SWIR GSD. Geometric error maps for each assessed VNIR band combination for the Boulder image, as well as the corresponding histogram graphs, are shown in figures 3 through 8 . The geometric error maps indicate the directional shift and relative magnitude of the shift, whereas the histogram graphs indicate frequency of observed mean error measurements within the image. Geometric error maps for each assessed SWIR band combination for the Longmont image, as well as the corresponding histogram graphs, are shown in figures 9 through 17. Together, the interior and exterior geometric analysis results, as reported in the "Interior (Band to Band)" and "Exterior (Geometric Location Accuracy)" sections, provide a comprehensive assessment of geometric accuracy.

Table 4. Band-to-band registration error.

[STD, standard deviation; Colo., Colorado; m, meter; NIR, near infrared; SWIR, shortwave infrared]

\begin{tabular}{|c|c|c|c|c|c|}
\hline Image & Band combination & Mean error (easting) & Mean error (northing) & STD (easting) & STD (northing) \\
\hline \multirow[t]{4}{*}{ Boulder, Colo. } & \multirow[t]{2}{*}{ Blue-green } & 0.006 pixel & -0.014 pixel & 0.047 pixel & 0.071 pixel \\
\hline & & $(0.005 \mathrm{~m})$ & $(-0.011 \mathrm{~m})$ & $(0.038 \mathrm{~m})$ & $(0.057 \mathrm{~m})$ \\
\hline & Green-yellow & $(-0.030 \mathrm{~m})$ & $(0.016 \mathrm{~m})$ & $(0.075 \mathrm{~m})$ & $(0.081 \mathrm{~m})$ \\
\hline & NIR 1-NIR 2 & -0.053 pixel & -0.011 pixel & 0.122 pixel & 0.260 pixel \\
\hline \multirow{4}{*}{ Fort Lupton, Colo. } & Blue-green & $(0.024 \mathrm{~m})$ & $(0.040 \mathrm{~m})$ & $(0.005 \mathrm{~m})$ & $(0.005 \mathrm{~m})$ \\
\hline & \multirow[t]{2}{*}{ Green-yellow } & 0.010 pixel & 0.010 pixel & 0.030 pixel & 0.050 pixel \\
\hline & & $(0.008 \mathrm{~m})$ & $(0.008 \mathrm{~m})$ & $(0.024 \mathrm{~m})$ & $(0.040 \mathrm{~m})$ \\
\hline & NIR 1-NIR 2 & -0.030 pixel & -0.070 pixel & 0.090 pixel & 0.180 pixel \\
\hline \multirow{4}{*}{ Longmont, Colo. } & \multirow[t]{2}{*}{ Green-yellow } & -0.020 pixel & 0.020 pixel & 0.040 pixel & 0.050 pixel \\
\hline & & $(-0.016 \mathrm{~m})$ & $(0.016 \mathrm{~m})$ & $(0.032 \mathrm{~m})$ & $(0.040 \mathrm{~m})$ \\
\hline & \multirow[t]{2}{*}{ NIR 1-NIR 2} & 0.050 pixel & 0.020 pixel & 0.090 pixel & 0.190 pixel \\
\hline & & $(0.040 \mathrm{~m})$ & $(0.016 \mathrm{~m})$ & $(0.073 \mathrm{~m})$ & $(0.153 \mathrm{~m})$ \\
\hline \multirow[t]{5}{*}{ Longmont, Colo. (SWIR) } & \multirow[t]{2}{*}{ SWIR 2-SWIR 3} & 0.089 pixel & 0.041 pixel & 0.518 pixel & 0.6814 pixel \\
\hline & & $(0.024 \mathrm{~m})$ & $(0.011 \mathrm{~m})$ & $(0.140 \mathrm{~m})$ & $(0.184 \mathrm{~m})$ \\
\hline & \multirow[t]{2}{*}{ SWIR 5-SWIR 6} & -0.015 pixel & 0.229 pixel & 0.503 pixel & 0.659 pixel \\
\hline & & $(-0.004 \mathrm{~m})$ & $(0.062 \mathrm{~m})$ & $(0.136 \mathrm{~m})$ & $(0.178 \mathrm{~m})$ \\
\hline & SWIR 6-SWIR 7 & 0.111 pixel & 0.426 pixel & 0.511 pixel & 0.714 pixel \\
\hline
\end{tabular}




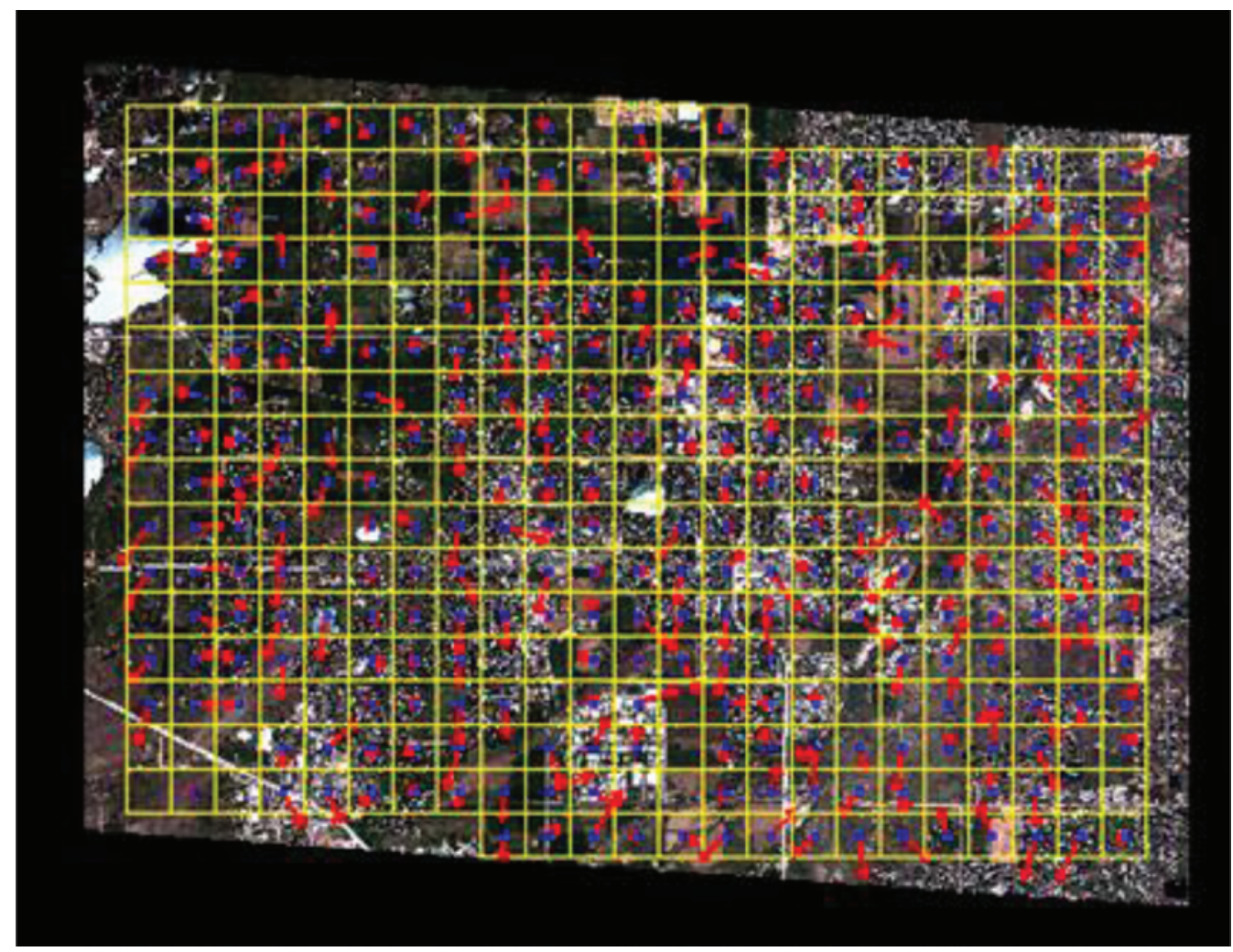

\section{EXPLANATION}

- Easting error

- Northing error

Grid

Figure 3. Band 2 (blue) to band 3 (green) geometric error map of Boulder, Colorado.

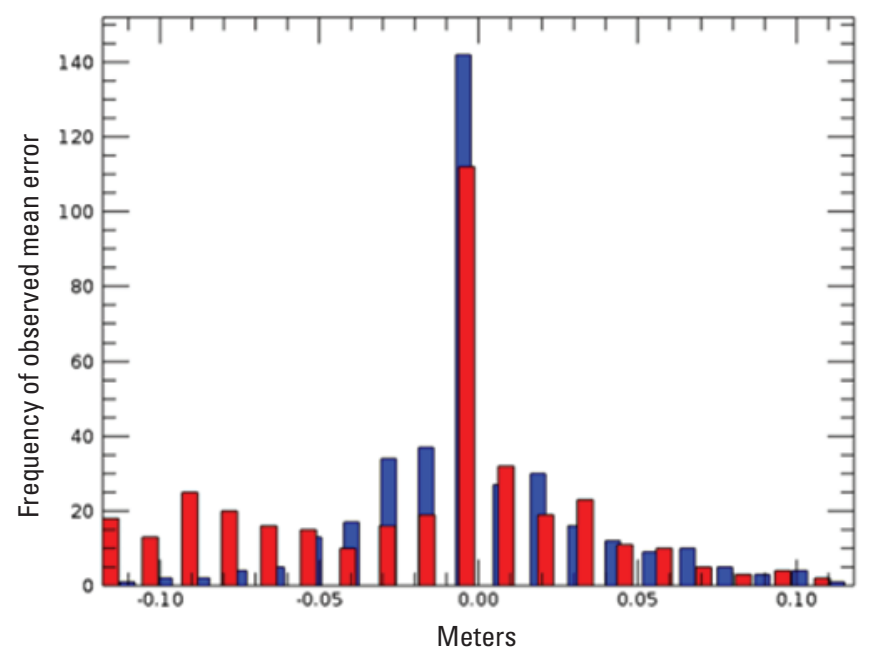

EXPLANATION

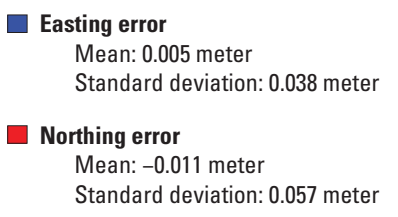

Figure 4. Band 2 (blue) to band 3 (green) geometric error histogram for Boulder, Colorado.

\section{Exterior (Geometric Location Accuracy)}

The exterior or geometric location accuracy was completed on the same three WorldView-3 images as described previously: Boulder image, Fort Lupton image, and Longmont image. For this analysis, band 7 (near infrared [NIR] 1) of the WorldView-3 data was compared against the corresponding band from three Sentinel-2 images over the United States, Boulder image (Colorado; scene identifier S2A_MSIL1C_20200526T174911_N0209_R141 T13TDE_20200526T212758), Fort Lupton image (Colorado; scene identifier S2A_MSIL1C_20190502T174911_ N0207_R141_T13TDE_20190502T213127),

and Longmont, image (Colorado; scene identifier S2B MSIL1C 20180810T174859_N0206_R141 T13TDE_20180810T212348). Additionally, SWIR 3 of the WorldView-3 data was compared against the corresponding band from one Sentinel-2 image over Longmont (Colorado; scene identifier S2B_MSIL1C_20180810T174859_N0206 R141_T13TDE_20180810T212348). Conjugate points in the reference and search images were identified automatically and refined using similarity measures such as normalized crosscorrelation metrics, and the mean error and standard deviation results are listed in table 5 with results represented in 


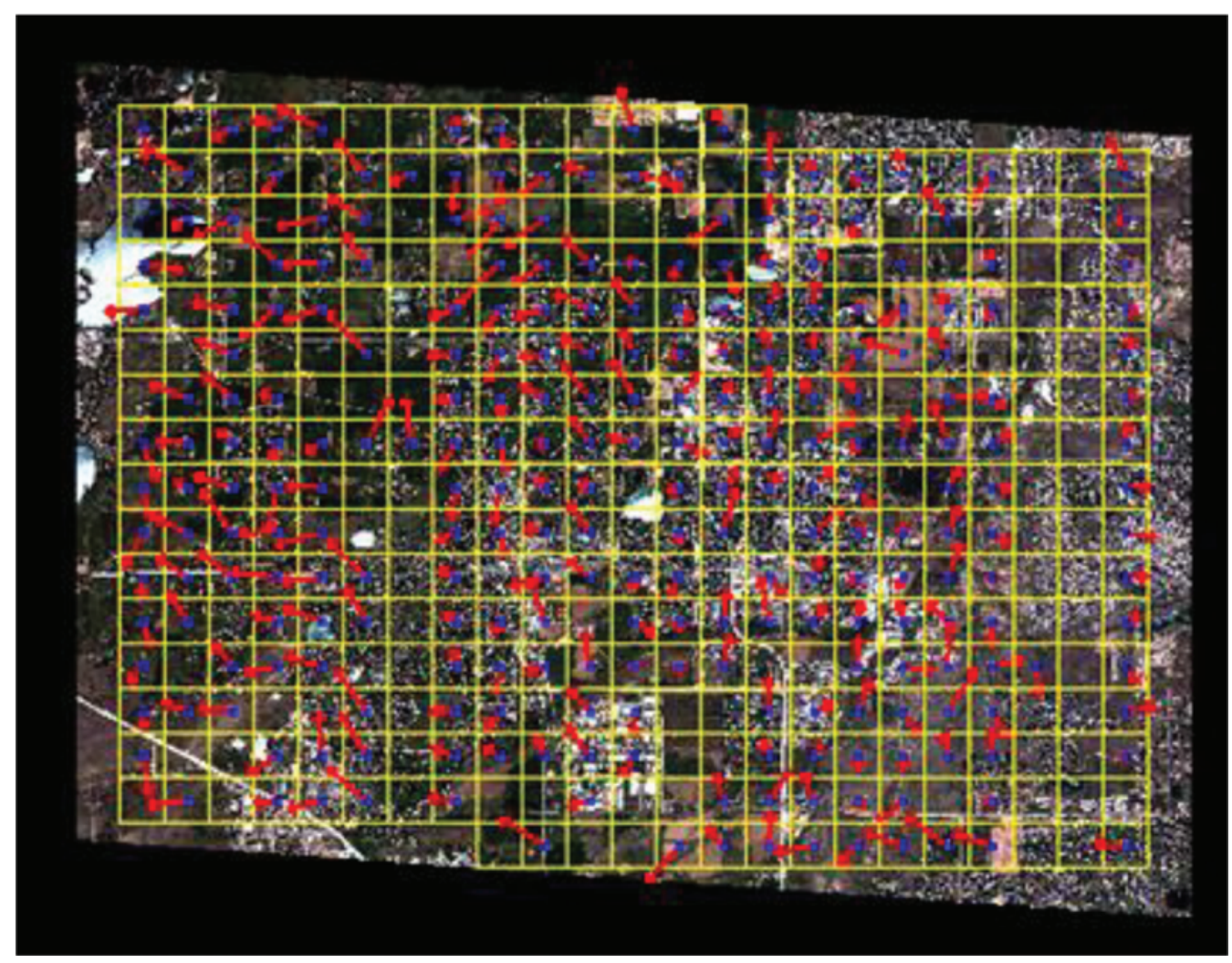

EXPLANATION

Easting error

- Northing error

Grid

Figure 5. Band 3 (green) to band 4 (yellow) geometric error map of Boulder, Colorado.

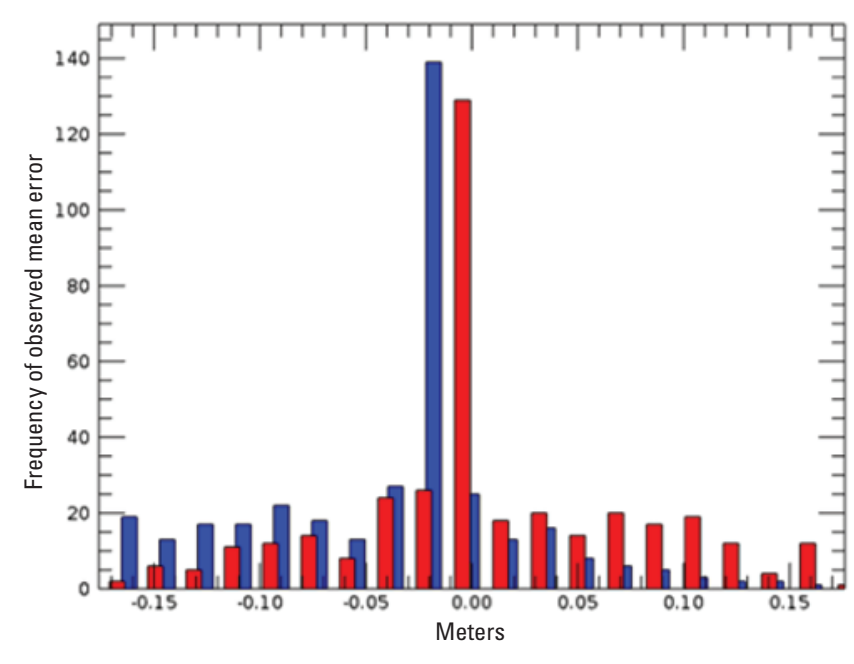

EXPLANATION

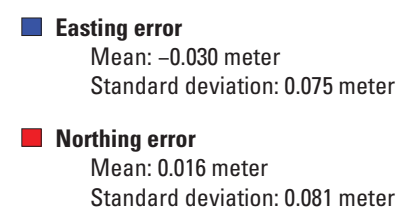

Figure 6. Band 3 (green) to band 4 (yellow) geometric error histogram for Boulder, Colorado. pixels at a 10-m GSD. For each of the three images, geometric error maps showing the directional shift and relative magnitude of the shift, when compared with Sentinel-2, along with the corresponding histogram graphs, are provided in figures 18 through 29. The Sentinel-2 imagery had a control uncertainty of about $8 \mathrm{~m}$.

\section{Radiometric Performance}

Radiometric performance was evaluated using linear regression. For this analysis, cloud-free regions of interest were selected within three near-coincident WorldView-3 and Sentinel-2 scene pairs over sites in the United States: Boulder (Colorado; WorldView-3 scene identifier 20MAY26181014-M1BS-013079068010_01_P002, Sentinel-2 scene identifier S2A_MSIL1C_20200526T174911_ N0209_R141_T13TDE_20200526T212758), Fort Lupton (Colorado; WorldView-3 scene identifier 19MAY02182702M1BS-013136294010_01_P001, Sentinel-2 scene identifier S2A_MSIL1C_20190502T174911_N0207_R141 T13TDE_20190502T213127), and Longmont (Colorado; WorldView-3 scene identifier 18AUG10180726M1BS-013107057010_01_P002, Sentinel-2 scene identifier S2B_MSIL1C_20180810T174859_N0206_ 


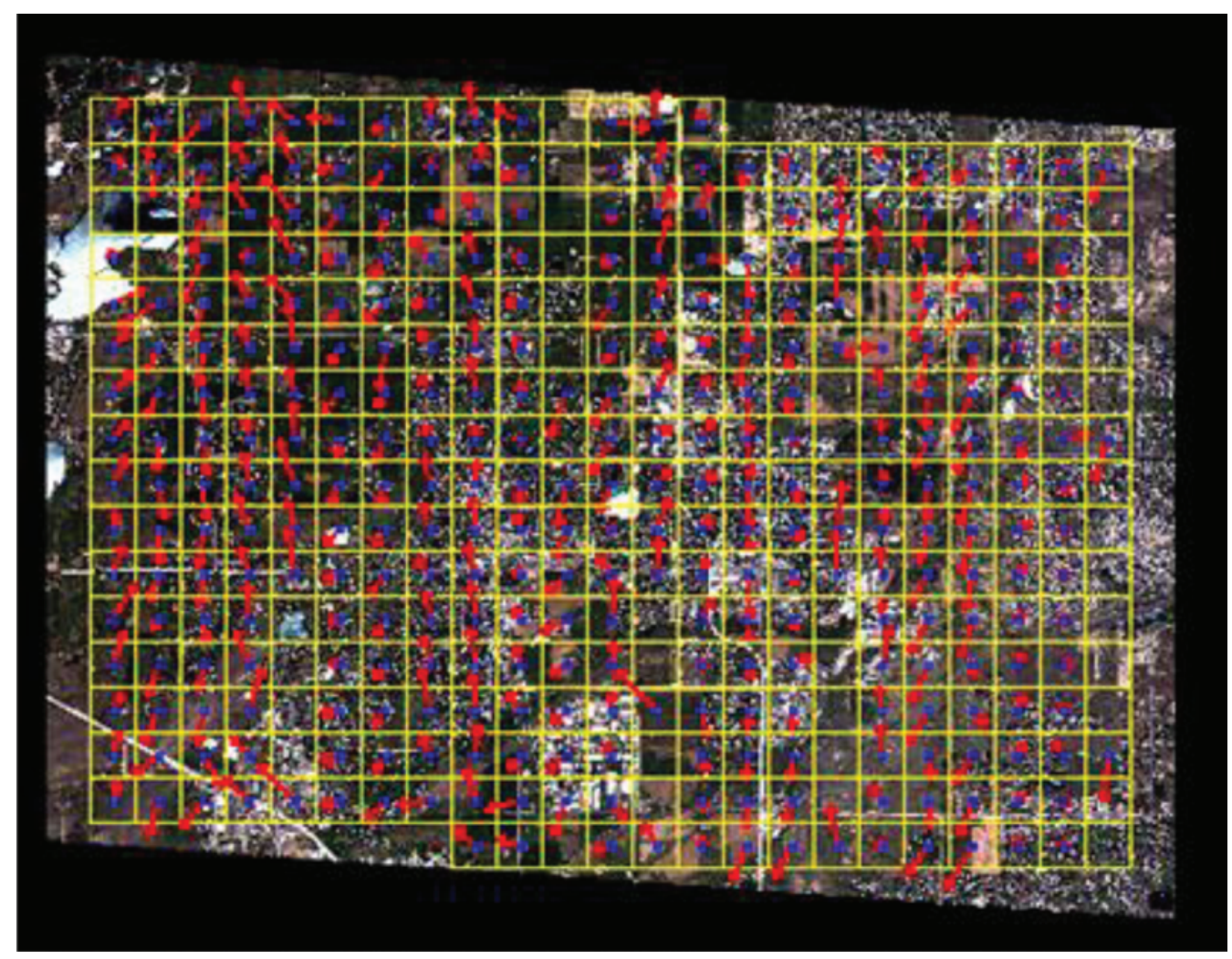

EXPLANATION

Easting error

Northing error Grid

Figure 7. Band 7 (near infrared 1) to band 8 (near infrared 2) geometric error map of Boulder, Colorado.

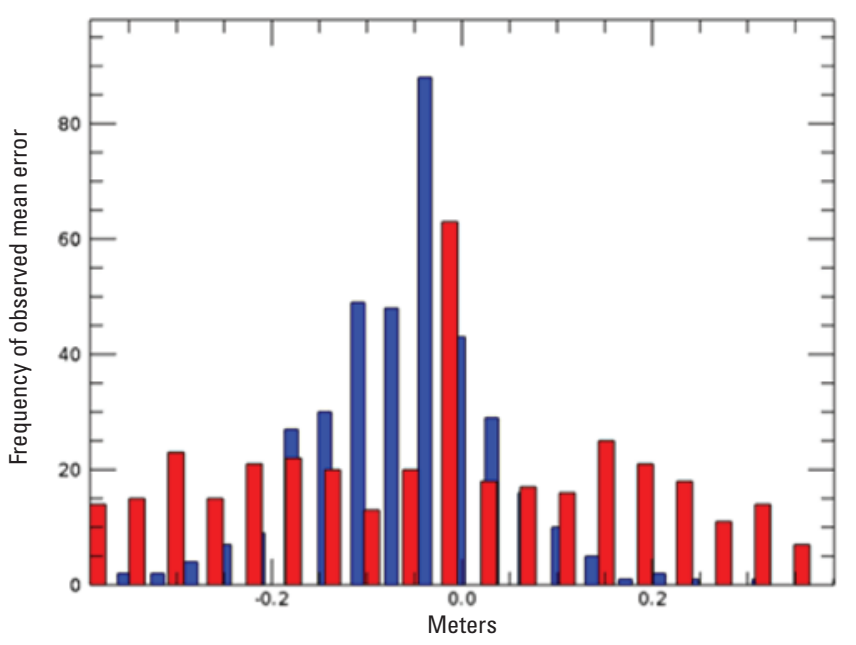

EXPLANATION

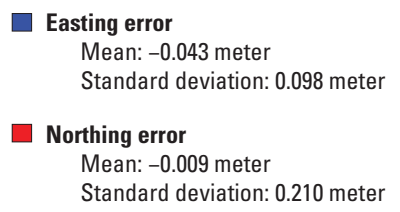

Figure 8. Band 7 (near infrared 1) to band 8 (near infrared 2) geometric error histogram for Boulder, Colorado.
R141_T13TDE_20180810T212348). Once the relative georeferencing error between Sentinel-2 and WorldView-3 has been corrected, Top of Atmosphere reflectance values from the two sensors are extracted. The scatterplots shown in figures 30-33 are drawn in a way that the $\mathrm{x}$-axis is the reference sensor and the y-axis is the comparison sensor. The linear regression, thus, represents Top of Atmosphere reflectance relative to that of the reference sensor. Ideally, slope should be near unity, and the offset should be near zero; for example, if the slope is greater than unity, that means the comparison sensor has a tendency to overestimate Top of Atmosphere reflectance compared to the reference sensor.

Top of Atmosphere reflectance comparison results for VNIR bands are listed in table 6. Top of Atmosphere reflectance comparison results for SWIR bands are listed in table 7 . WorldView VNIR bands 2, 3, 5, and 7, along with SWIR bands 3 and 7, were chosen because they each correlate well with a corresponding Sentinel-2 band. A VNIR band-toband graphical comparison between the WorldView-3 image over Boulder, Colo., when compared with the corresponding Sentinel-2 band, is shown in figure 30. A VNIR band-by-band comparison for the image over Fort Lupton, Colo., is shown in figure 31, a comparison over Longmont, Colo., is shown in figure 32, and a comparison of WorldView-3 and Sentinel-2 SWIR bands over Longmont, Colo., is shown in figure 33. 


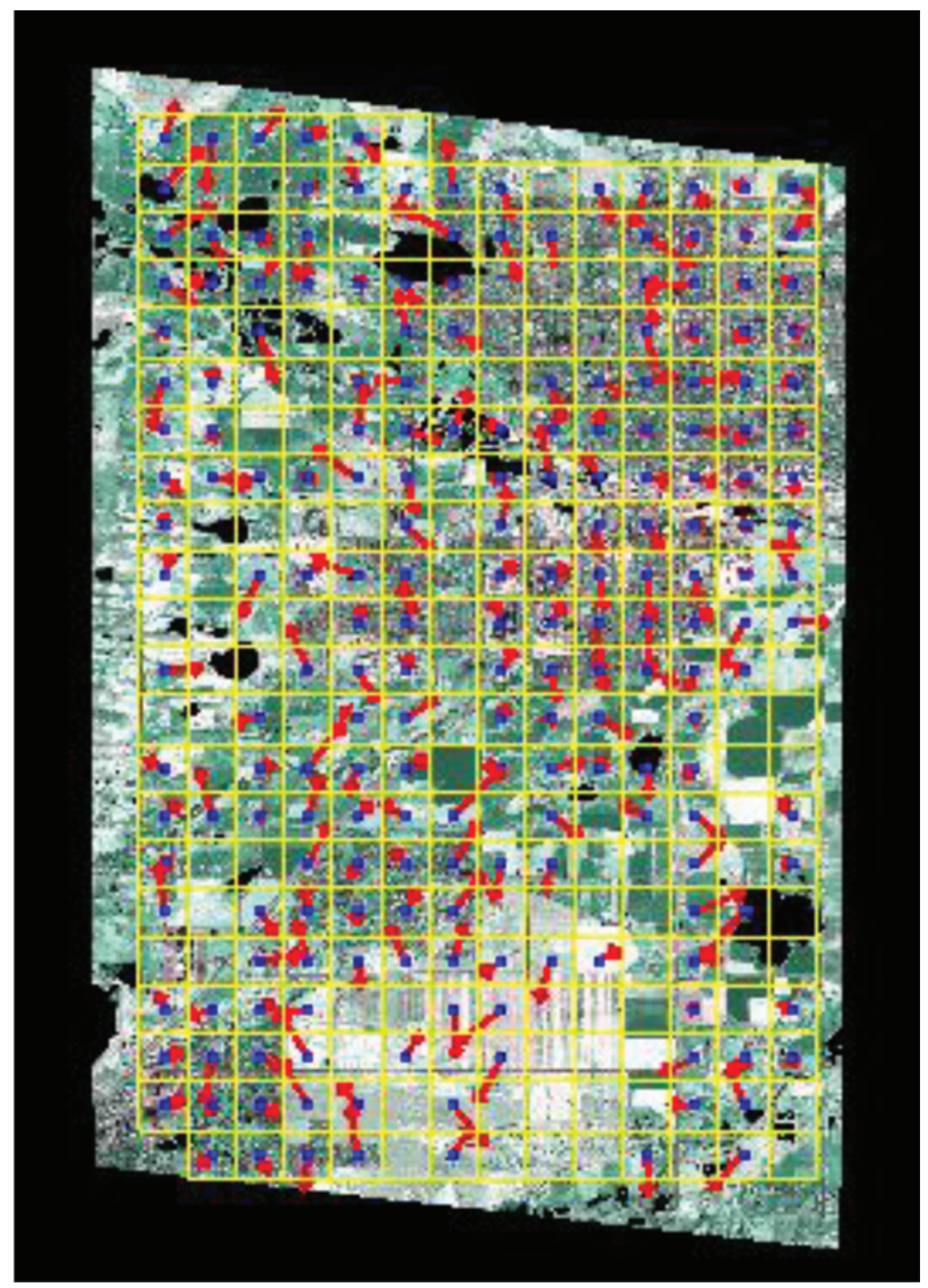

\section{EXPLANATION}

- Easting error

- Northing error

Grid

Figure 9. Shortwave infrared 2 to shortwave infrared 3 geometric error map of Longmont, Colorado.

\section{Spatial Performance}

For this analysis, edge spread and line spread functions were calculated, with resulting full width at half maximum and modular transfer function at Nyquist frequency analysis outputs, as listed in table 8 . The band 2 (blue) edge spread and line spread function results using one WorldView-3 scene (18AUG18040033-M3DS_R2C2-010295774010_01_P001. TIF) for analysis are shown in figure 34 . The results for this WorldView-3 scene for band 3 (green) are shown in figure 35, the results for band 5 (red) are shown in figure 36 , and the results for band 7 (NIR 1) are shown in figure 37. 


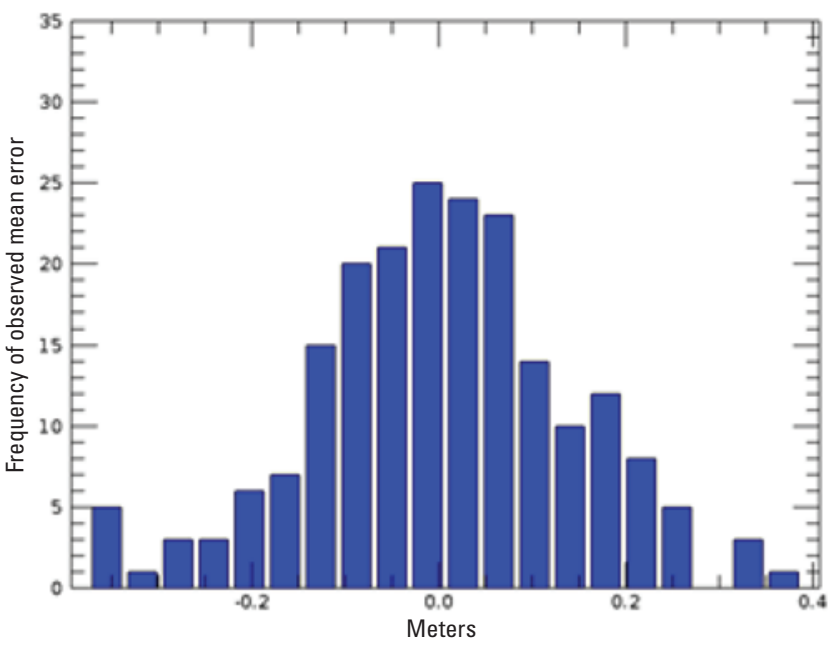

EXPLANATION

- Easting error

Mean: 0.024 meter

Standard deviation: 0.140 meter

Figure 10. Shortwave infrared 2 to shortwave infrared 3 geometric easting error histogram for Longmont, Colorado.

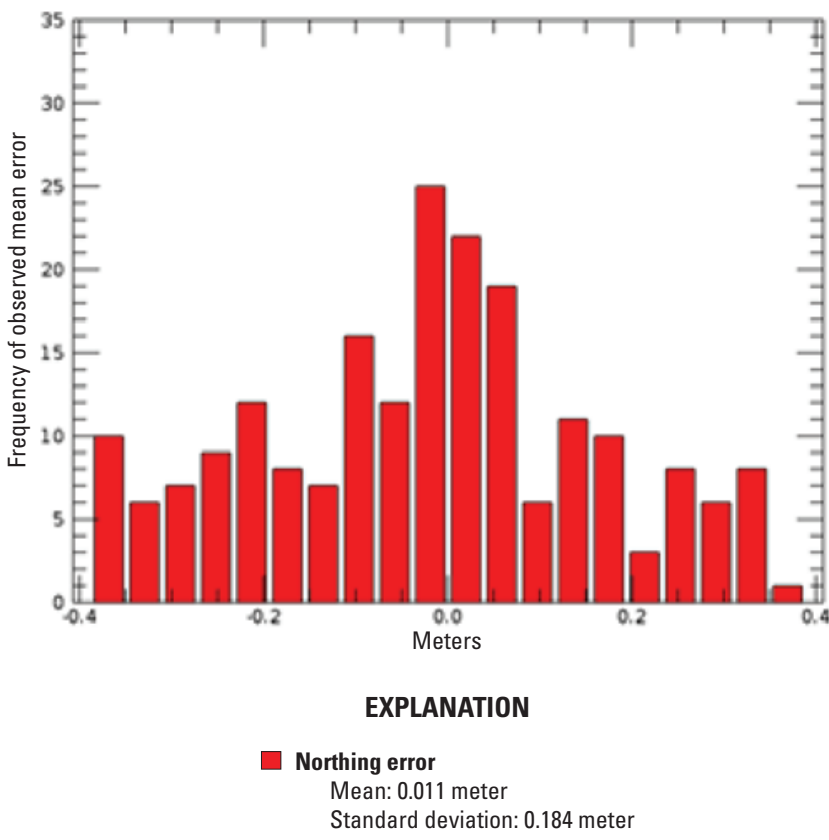

Figure 11. Shortwave infrared 2 to shortwave infrared 3 geometric northing error histogram for Longmont, Colorado. 


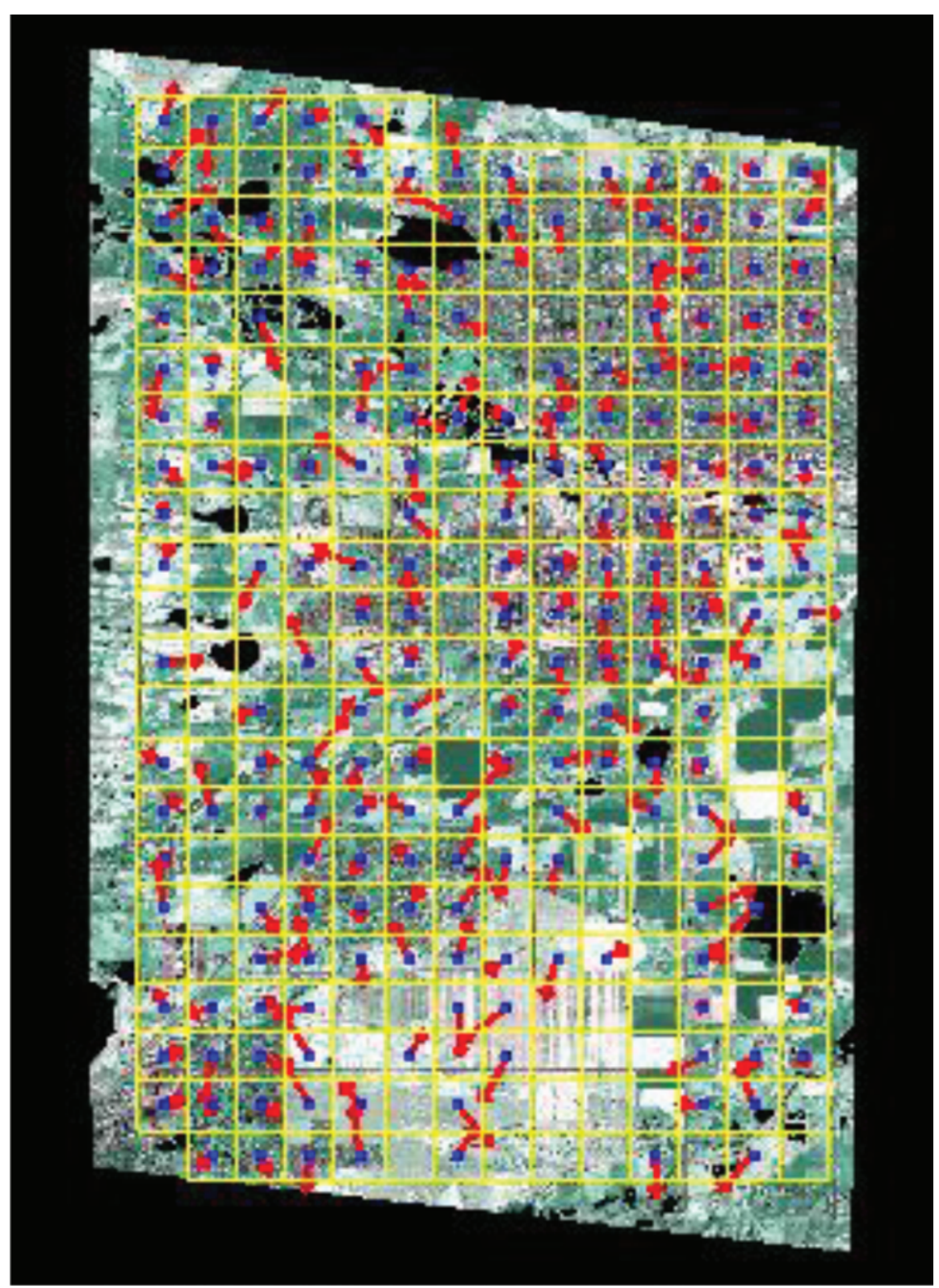

EXPLANATION

- Easting error

- Northing error Grid

Figure 12. Shortwave infrared 5 to shortwave infrared 6 geometric error map of Longmont, Colorado. 


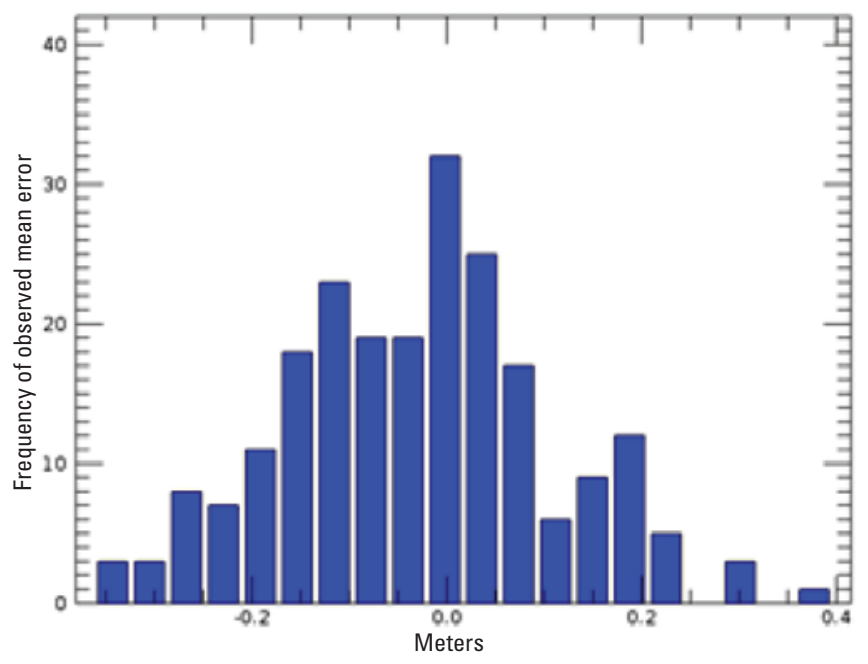

EXPLANATION

Easting error

Mean: -0.004 meter

Standard deviation: 0.136 meter

Figure 13. Shortwave infrared 5 to shortwave infrared 6 geometric easting error histogram for Longmont, Colorado.

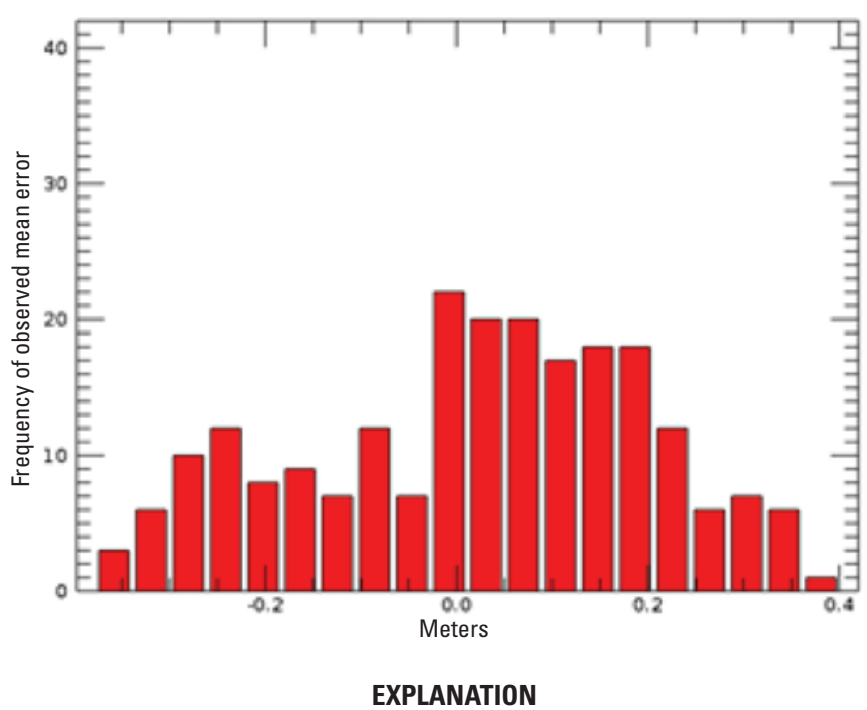

Northing error

Mean: 0.062 meter

Standard deviation: 0.178 meter

Figure 14. Shortwave infrared 5 to shortwave infrared 6 geometric northing error histogram for Longmont, Colorado. 


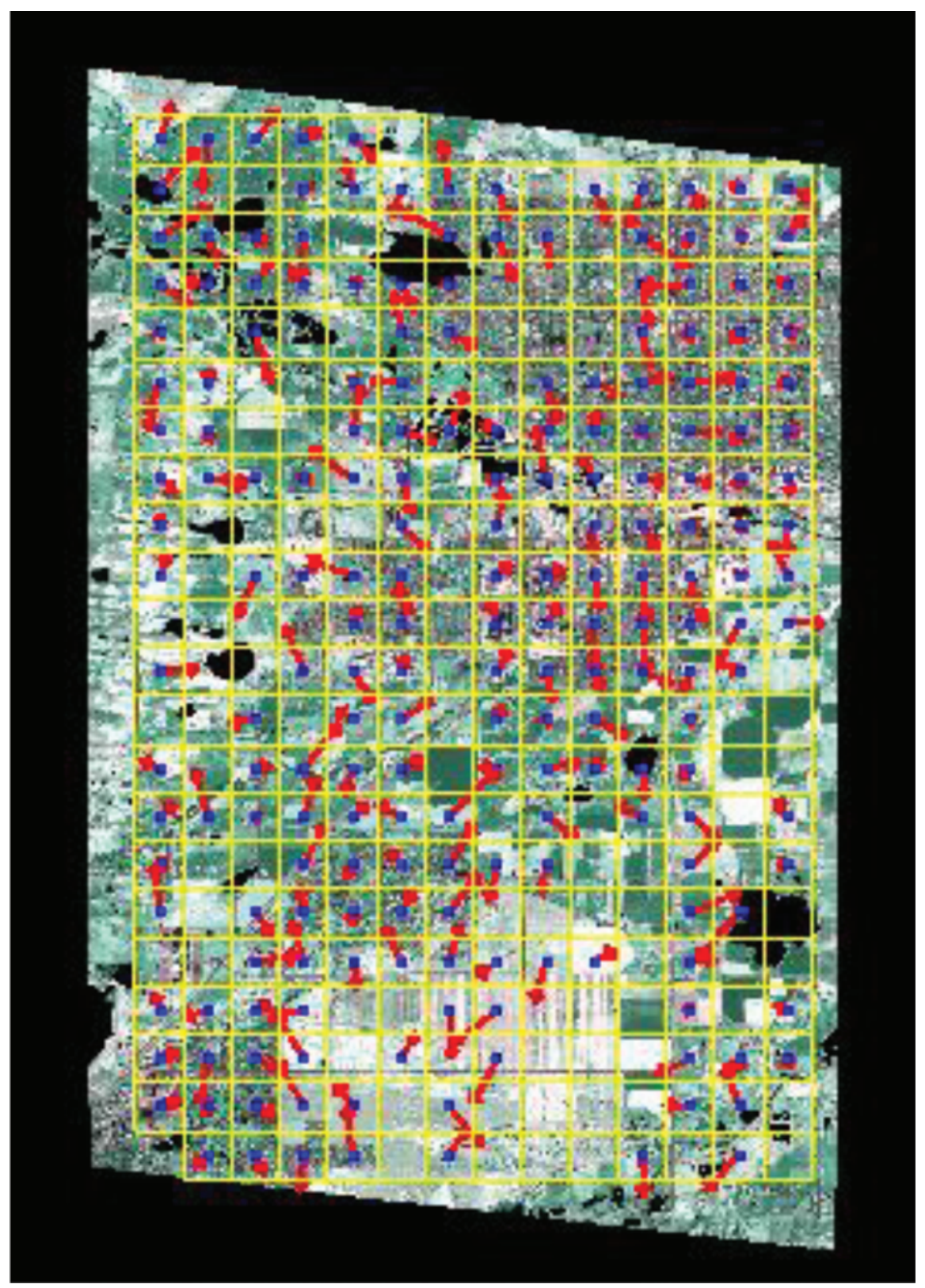

EXPLANATION

- Easting error

- Northing error

Grid

Figure 15. Shortwave infrared 6 to shortwave infrared 7 geometric error map of Longmont, Colorado. 


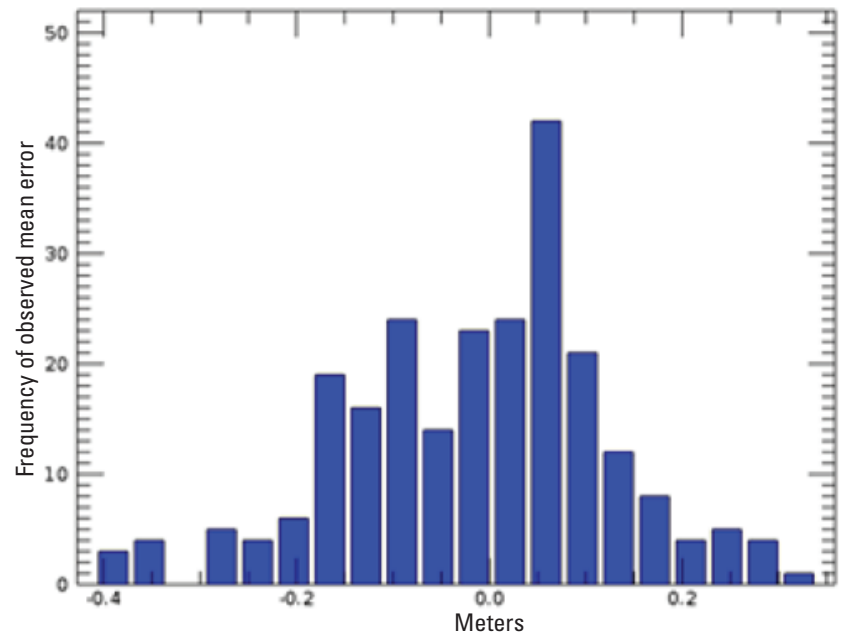

EXPLANATION

Easting error

Mean: 0.030 meter

Standard deviation: 0.138 meter

Figure 16. Shortwave infrared 6 to shortwave infrared 7 geometric easting error histogram for Longmont, Colorado.

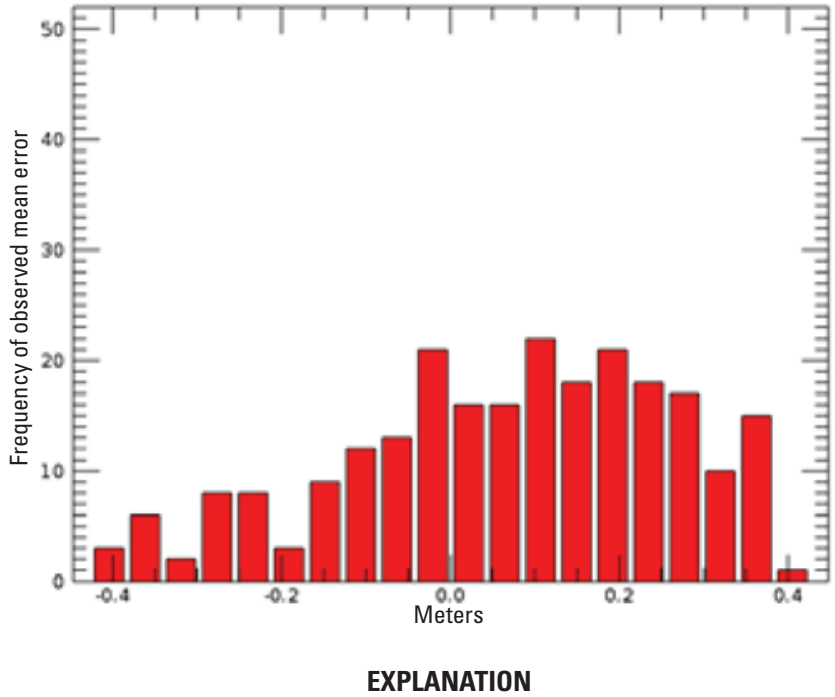

Northing error

Mean: 0.115 meter

Standard deviation: 0.193 meter

Figure 17. Shortwave infrared 6 to shortwave infrared 7 geometric northing error histogram for Longmont, Colorado.

Table 5. Geometric error relative to Sentinel-2.

[ID, identifier; STD, standard deviation; Colo., Colorado; NIR, near infrared; m, meter; SWIR, shortwave infrared]

\begin{tabular}{lcccc}
\hline \multicolumn{1}{c}{ Scene IDs } & Mean error (easting) & Mean error (northing) & STD (easting) & STD (northing) \\
\hline 20MAY26181014- & -0.849 pixel & -2.117 pixels & 0.546 pixel & 2.120 pixels \\
M1BS-013079068010_01_P002 & $(-8.491 \mathrm{~m})$ & $(-21.167 \mathrm{~m})$ & $(5.463 \mathrm{~m})$ & $(21.196 \mathrm{~m})$ \\
$\begin{array}{l}\text { (Boulder, Colo.)-NIR 1 } \\
\text { 19MAY02182702- }\end{array}$ & 1.116 pixels & 2.311 pixels & 1.091 pixels & 2.501 pixels \\
M1BS-013136294010_01_P001 & $(11.156 \mathrm{~m})$ & $(23.105 \mathrm{~m})$ & $(10.914 \mathrm{~m})$ & $(25.007 \mathrm{~m})$ \\
(Fort Lupton, Colo.)_NIR 1 & 2.802 pixels & 1.873 pixels & 0.924 pixel & 0.847 pixel \\
18AUG10180726- & $(28.020 \mathrm{~m})$ & $(18.729 \mathrm{~m})$ & $(9.239 \mathrm{~m})$ & $(8.474 \mathrm{~m})$ \\
$\quad \begin{array}{l}\text { M1BS-013107057010_01_P002 } \\
\text { (Longmont, Colo.)-NIR 1 }\end{array}$ & 2.720 pixels & 1.990 pixels & 1.232 pixels & 1.204 pixels \\
$\begin{array}{l}\text { 18AUG10180728- } \\
\text { A1BS-013107058010_01_P001 }\end{array}$ & $(27.200 \mathrm{~m})$ & $(19.896 \mathrm{~m})$ & $(12.320 \mathrm{~m})$ & $(12.041 \mathrm{~m})$ \\
\hline
\end{tabular}




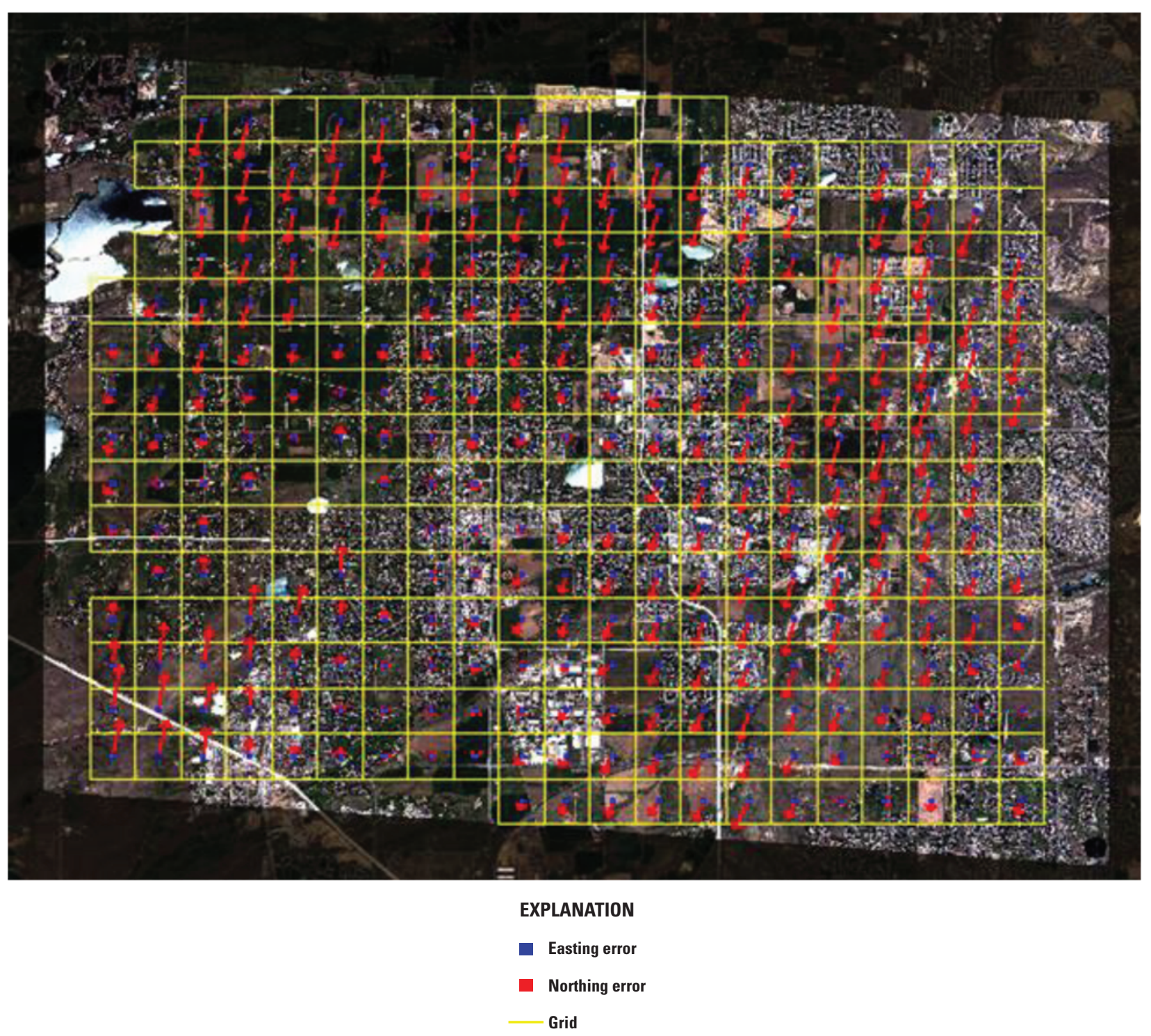

Figure 18. Relative geometric error comparison for Sentinel-2 and WorldView-3 for near infrared, Boulder, Colorado. 


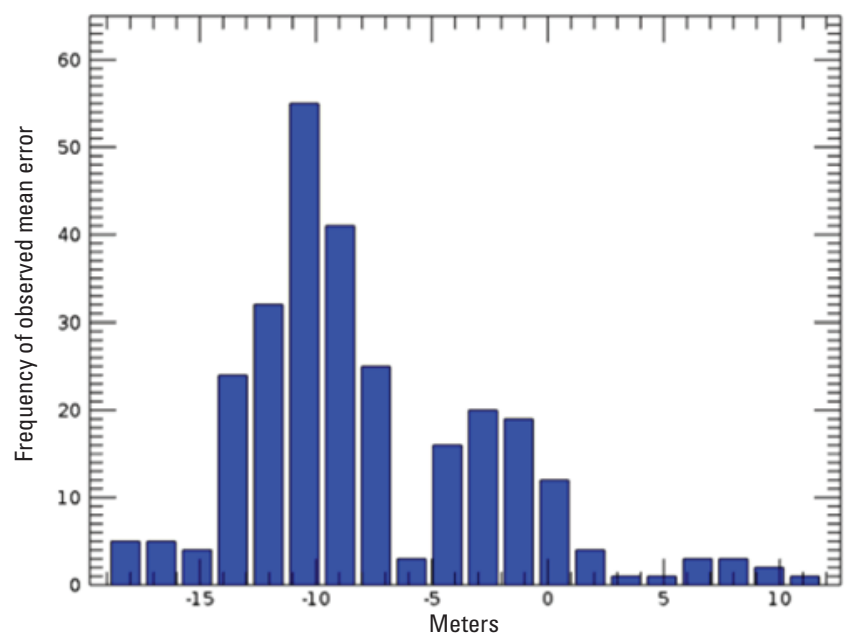

EXPLANATION

Easting error

Mean: -8.491 meters

Standard deviation: 5.463 meters

Figure 19. Relative geometric easting error histogram comparison for Sentinel-2 and WorldView-3 for near infrared, Boulder, Colorado.

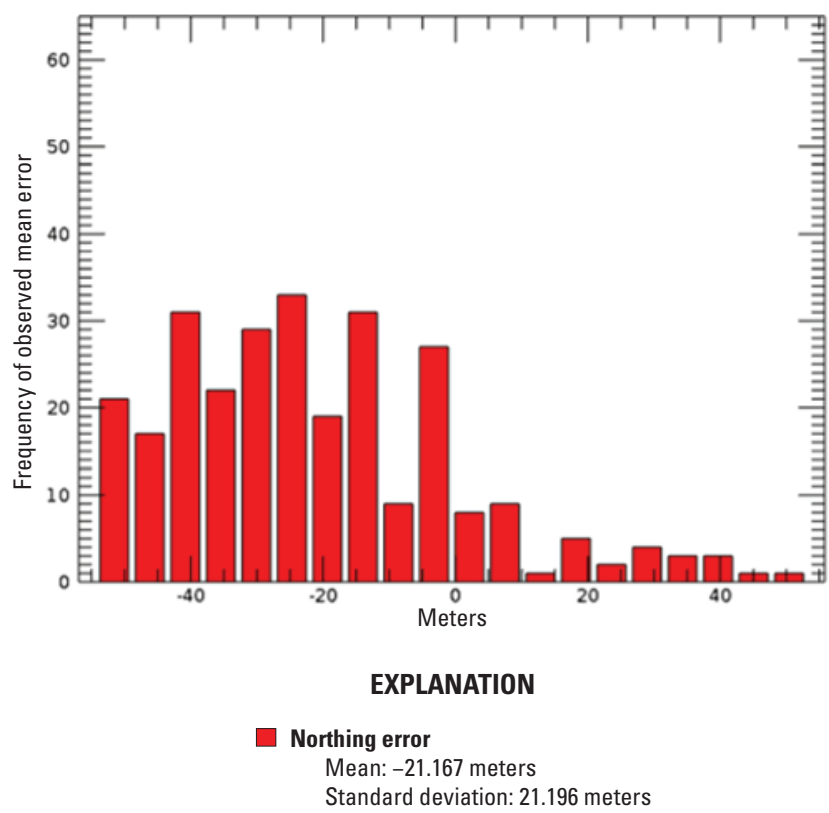

Figure 20. Relative geometric northing error histogram comparison for Sentinel-2 and WorldView-3 for near infrared, Boulder, Colorado. 


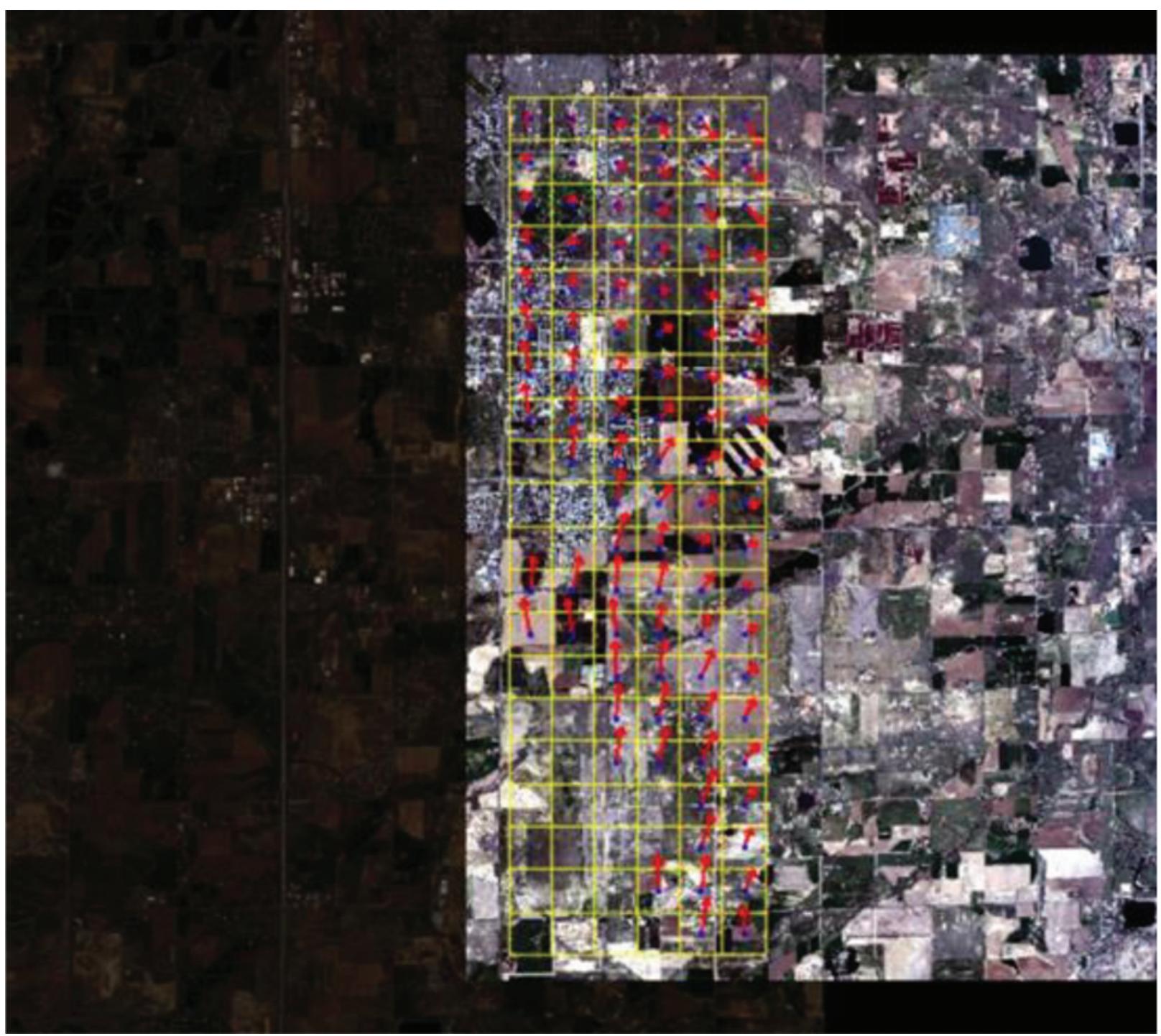

EXPLANATION
Easting error
northing error
Grid

Figure 21. Relative geometric error comparison for Sentinel-2 and WorldView-3 for near infrared, Fort Lupton, Colorado. 


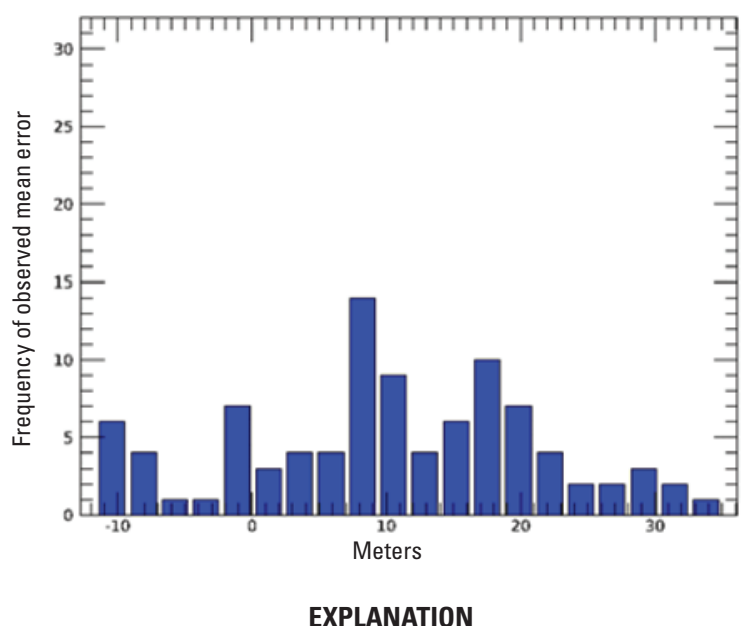

$\square$ Easting error

Mean: 11.156 meters

Standard deviation: 10.914 meters

Figure 22. Relative geometric easting error histogram comparison for Sentinel-2 and WorldView-3 for near infrared, Fort Lupton, Colorado.

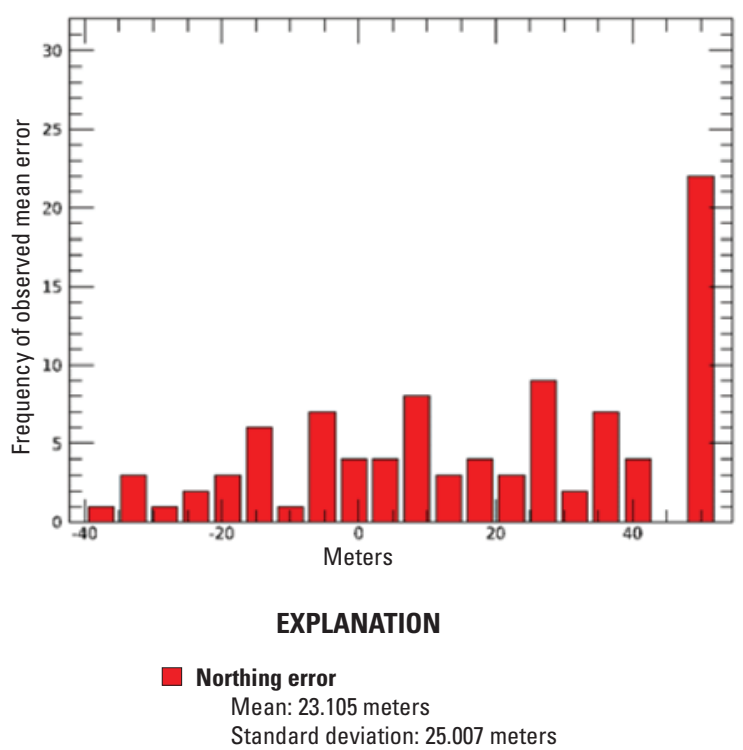

Figure 23. Relative geometric northing error histogram comparison for Sentinel-2 and WorldView-3 for near infrared, Fort Lupton, Colorado.

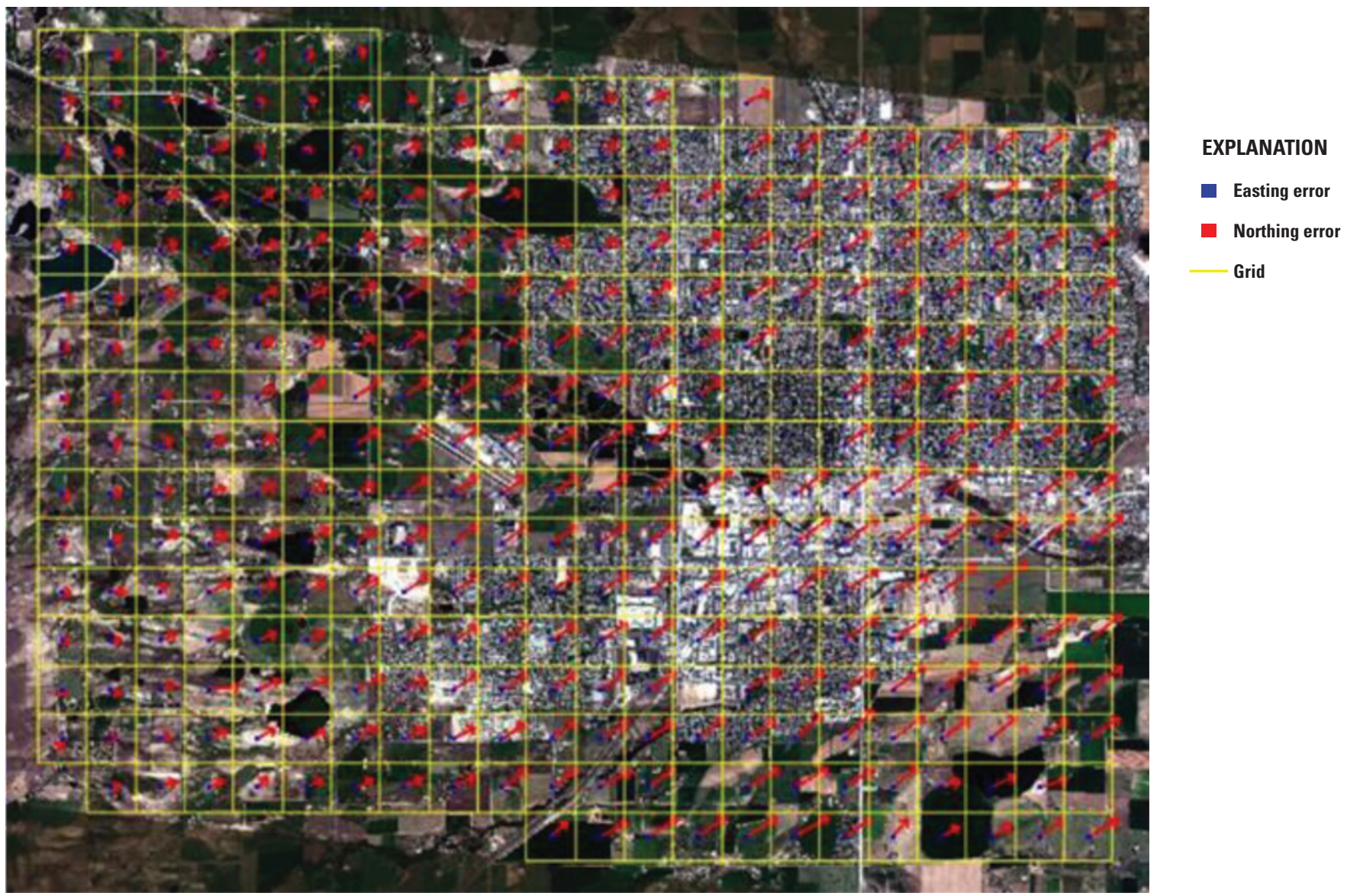

Figure 24. Relative geometric error comparison for Sentinel-2 and WorldView-3 for near infrared, Longmont, Colorado. 


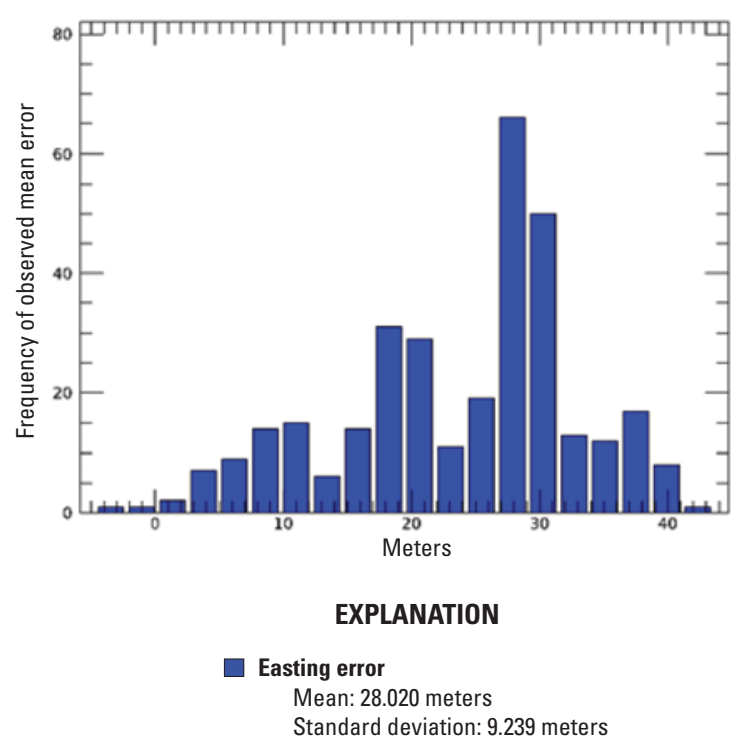

Figure 25. Relative geometric easting error histogram comparison for Sentinel-2 and WorldView-3 for near infrared, Longmont, Colorado.

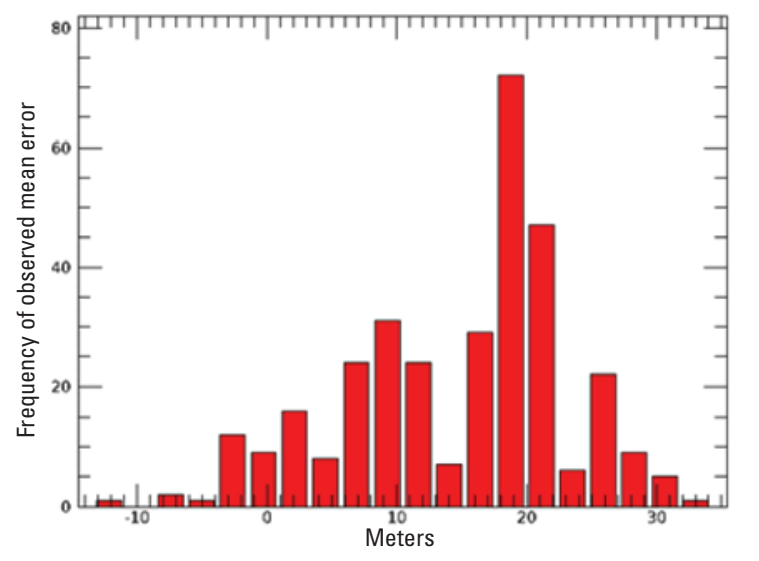

EXPLANATION

$\square$ Northing error

Mean: 18.729 meters

Standard deviation: 8.474 meters

Figure 26. Relative geometric northing error histogram comparison for Sentinel-2 and WorldView-3 for near infrared, Longmont, Colorado.

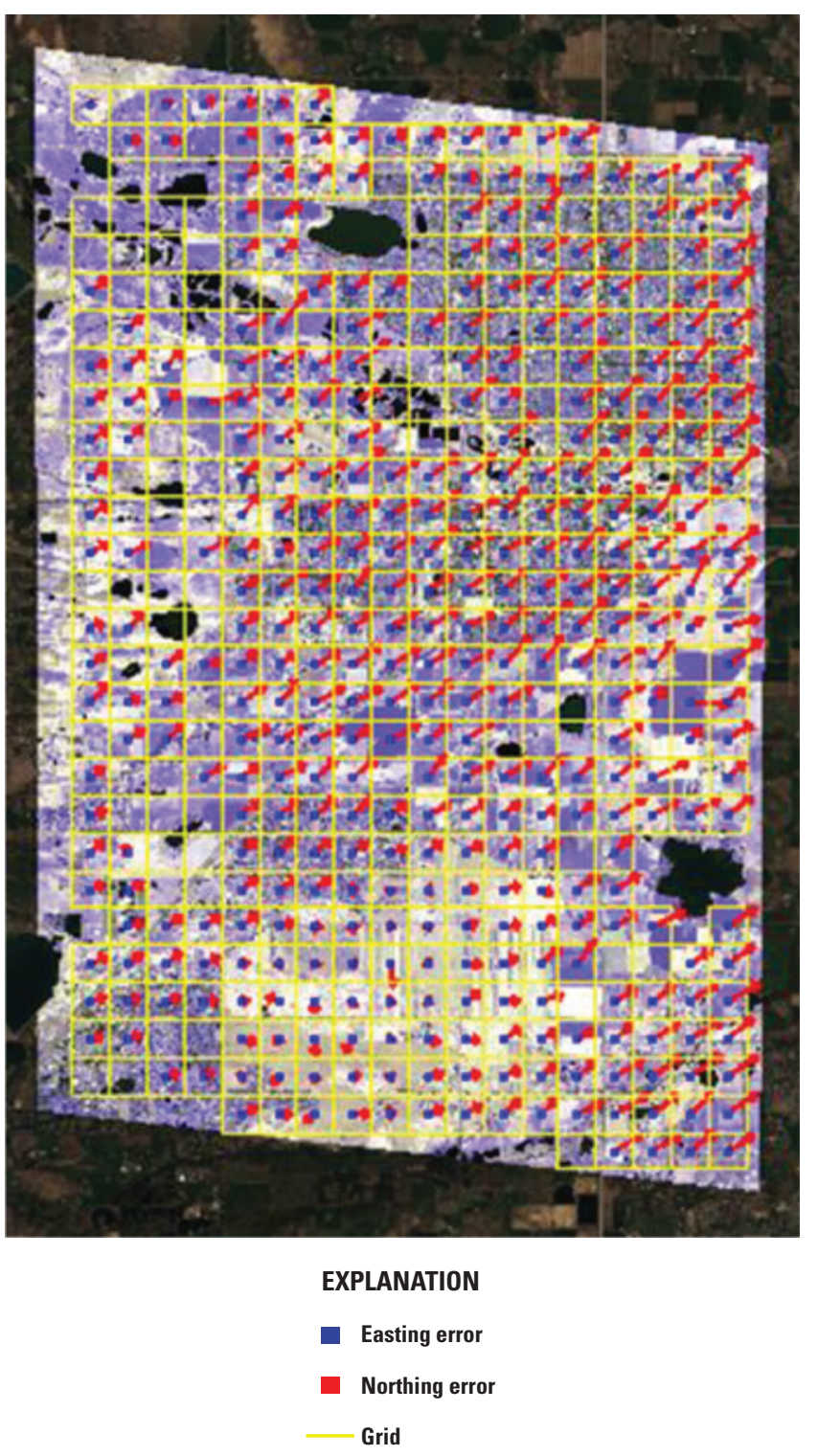

Figure 27. Relative geometric error comparison for Sentinel-2 and WorldView-3 for shortwave infrared, Longmont, Colorado. 


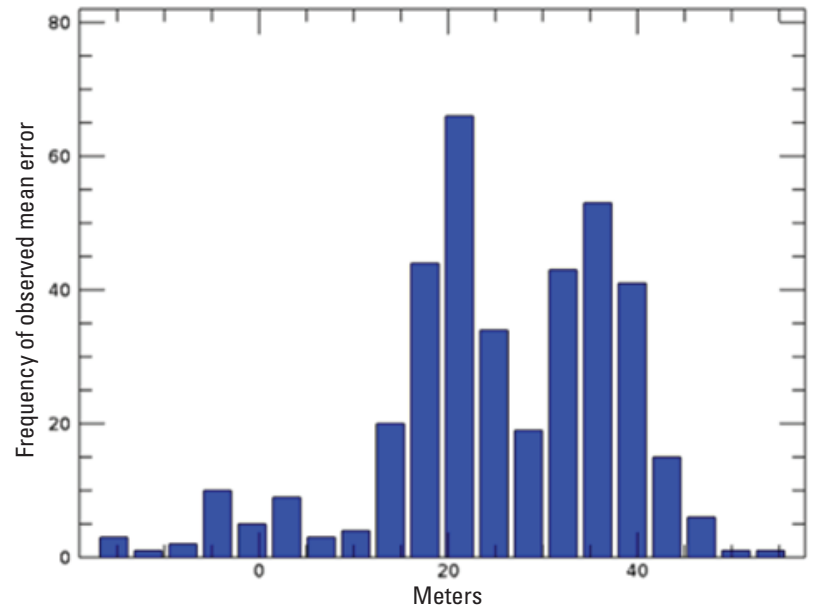

EXPLANATION

Easting error

Mean: 27.200 meters

Standard deviation: 12.320 meters

Figure 28. Relative geometric easting error histogram comparison for Sentinel-2 and WorldView-3 for shortwave infrared, Longmont, Colorado.

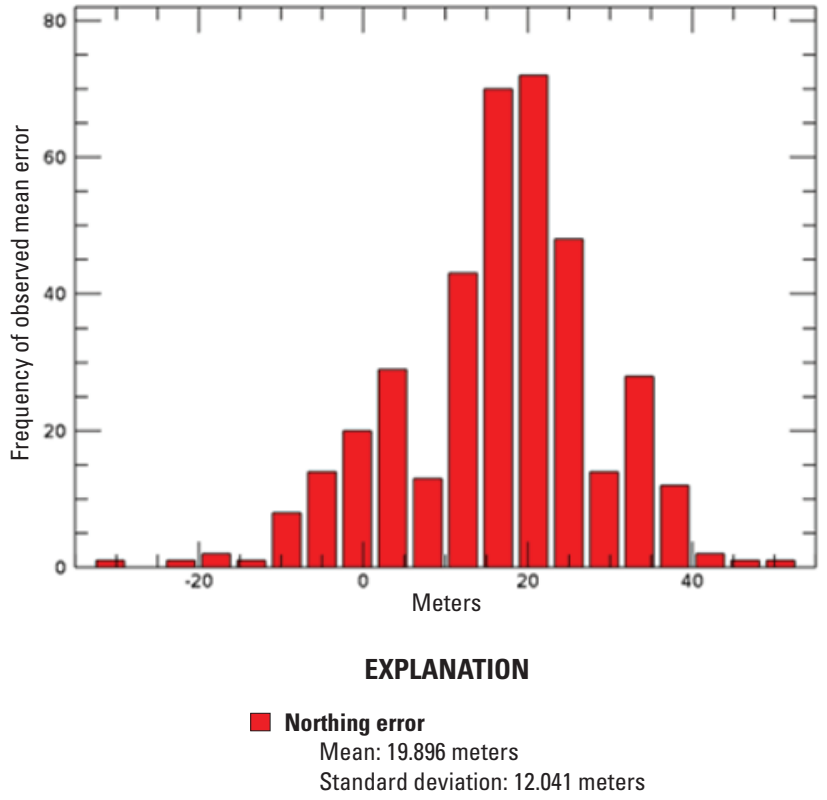

Figure 29. Relative geometric northing error histogram comparison for Sentinel-2 and WorldView-3 for shortwave infrared, Longmont, Colorado. 

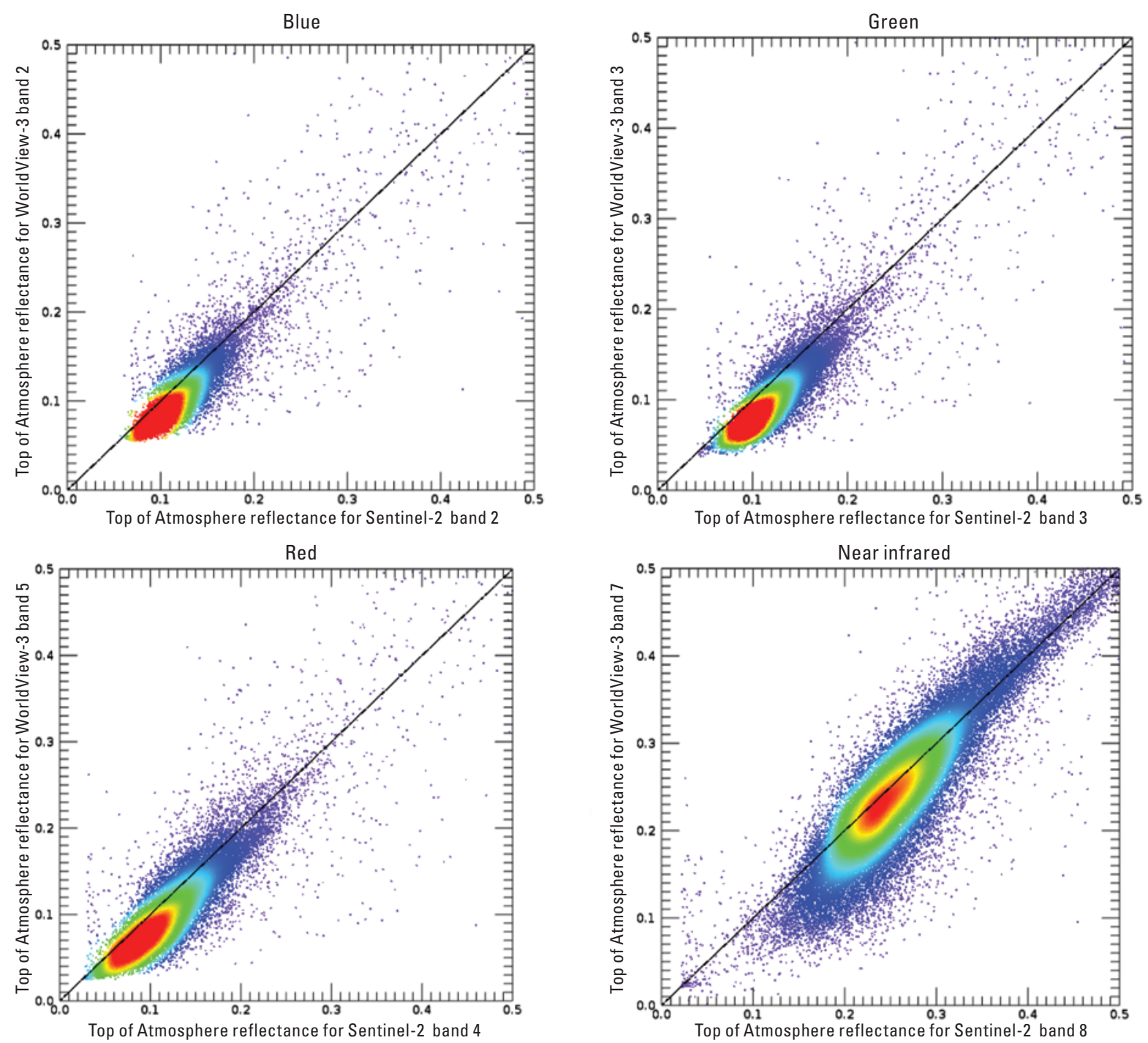

Figure 30. Top of Atmosphere reflectance comparison for WorldView-3 and Sentinel-2 for blue, green, red, and near-infrared bands for Boulder, Colorado. 

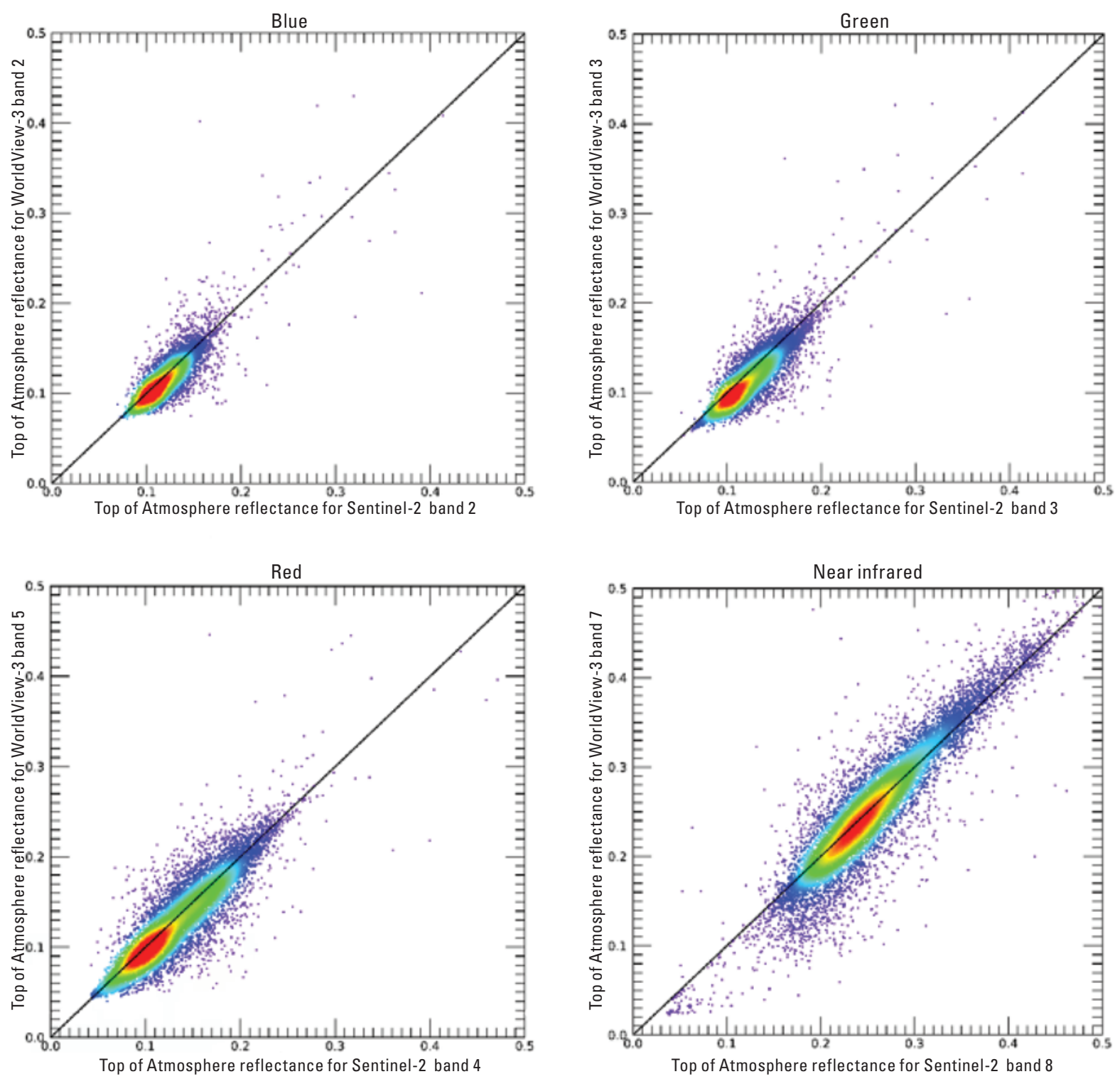

Figure 31. Top of Atmosphere reflectance comparison for WorldView-3 and Sentinel-2 for blue, green, red, and near-infrared bands for Fort Lupton, Colorado. 

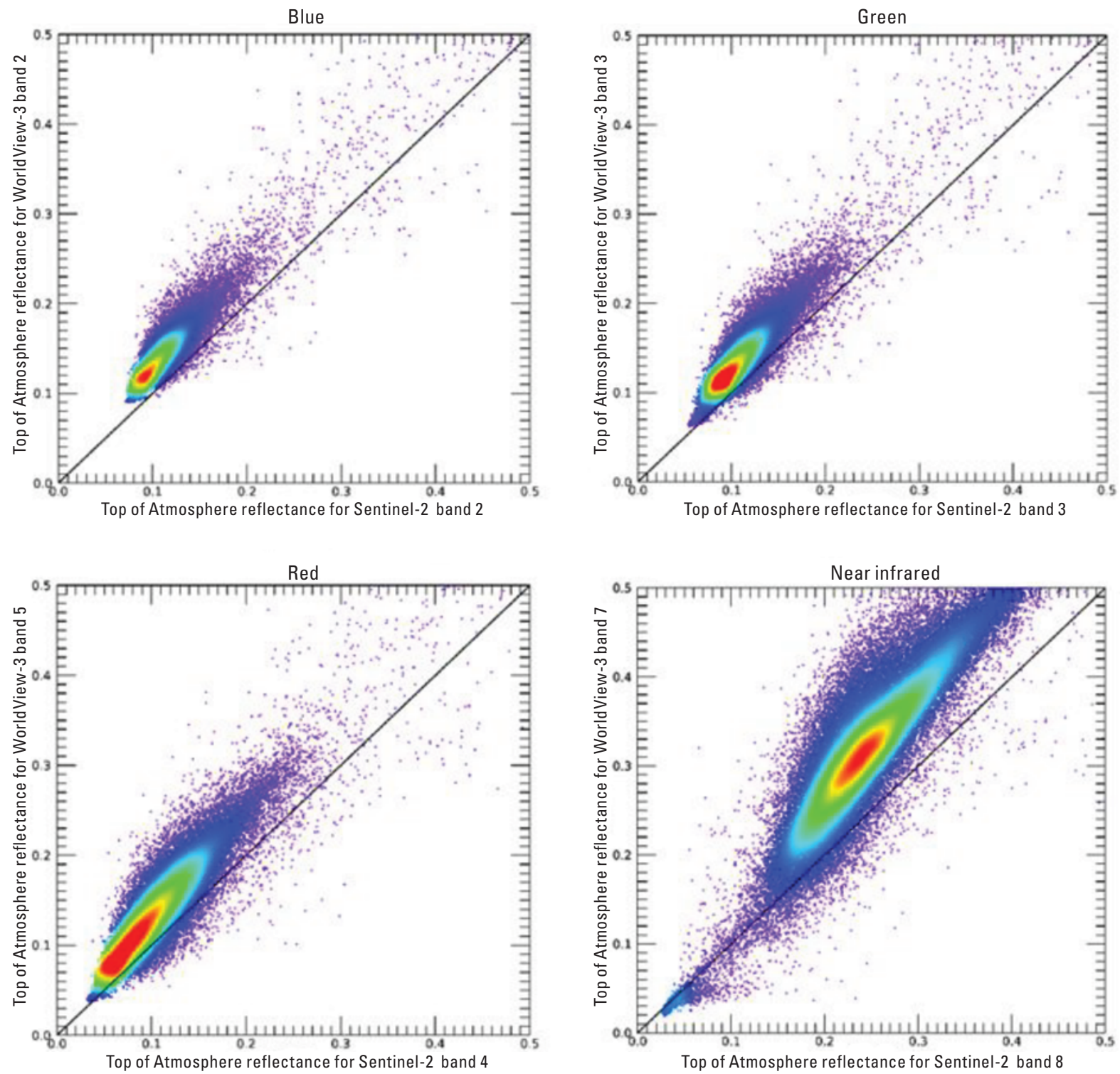

Figure 32. Top of Atmosphere reflectance comparison for WorldView-3 and Sentinel-2 for blue, green, red, and near-infrared bands for Longmont, Colorado. 

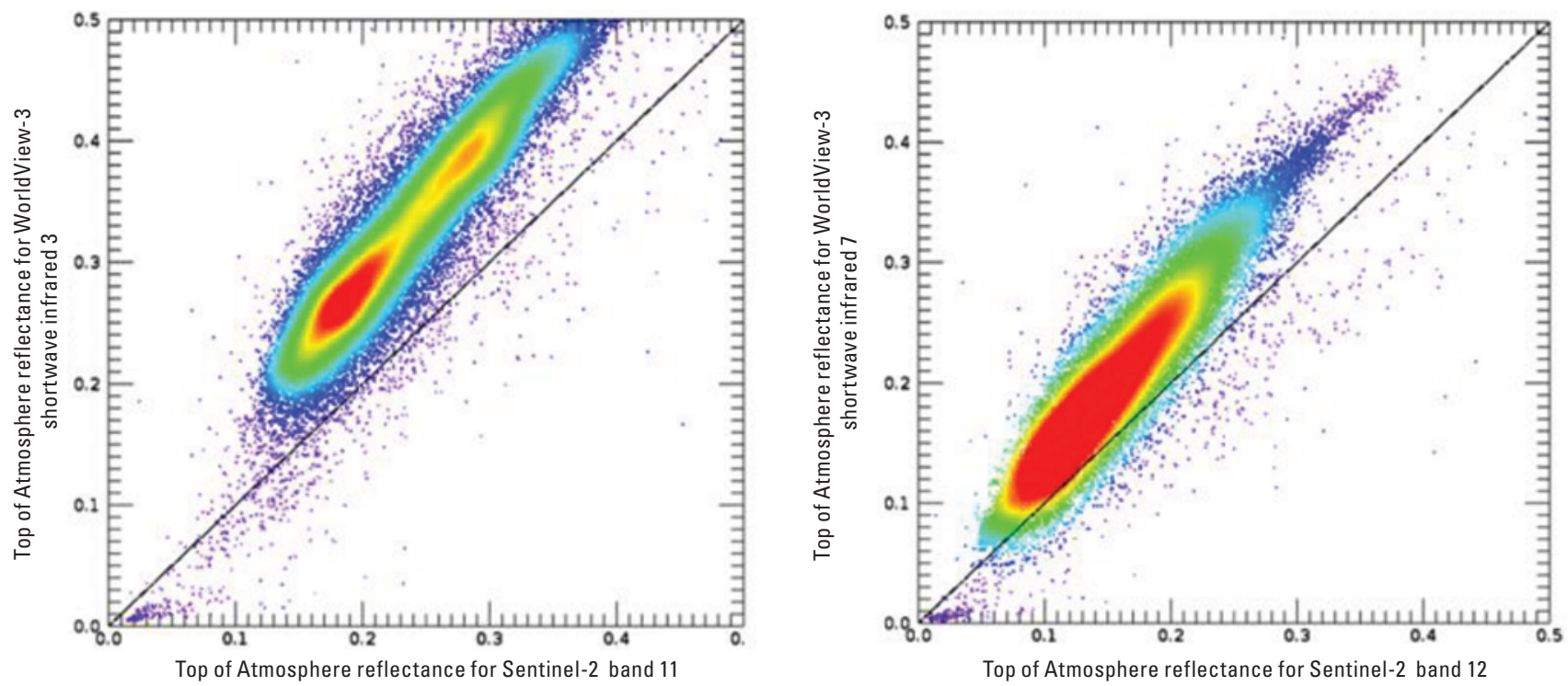

Figure 33. Top of Atmosphere reflectance comparison for WorldView-3 and Sentinel-2 for shortwave infrared 3 and shortwave infrared 7 for Longmont, Colorado.

Table 6. Top of Atmosphere reflectance comparison of WorldView-3 images against Sentinel-2 images.

[ID, identifier; NIR, near infrared; Colo., Colorado; \%, percent; $R^{2}$, coefficient of determination]

\begin{tabular}{|c|c|c|c|c|c|}
\hline Scene IDs & Statistics & Band 2-Blue & Band 3-Green & Band 5-Red & Band 7-NIR 1 \\
\hline \multirow{4}{*}{$\begin{array}{l}\text { Sentinel-2: S2A_ } \\
\text { MSIL1C_20200526T174911__ } \\
\text { N0209_R141_ } \\
\text { T13TDE_20200526T212758 } \\
\text { WorldView-3: 20MAY26181014- } \\
\text { M1BS-013079068010_01_P002 } \\
\text { (Boulder, Colo.) }\end{array}$} & Uncertainty (\%) & 10.270 & 11.240 & 16.080 & 12.240 \\
\hline & $R^{2}$ & 0.815 & 0.806 & 0.831 & 0.780 \\
\hline & Radical offset & -0.034 & -0.039 & -0.037 & -0.121 \\
\hline & Radical slope & 1.182 & 1.175 & 1.185 & 1.420 \\
\hline \multirow{4}{*}{$\begin{array}{l}\text { Senitnel-2: S2A_ } \\
\text { MSIL1C_20190502T174911_ } \\
\text { N0207_R141_ } \\
\text { T13TDE_20190502T213127 } \\
\text { WorldView-3: 19MAY02182702- } \\
\text { M1BS-013136294010_01_P001 } \\
\text { (Fort Lupton, Colo.) }\end{array}$} & Uncertainty (\%) & 6.710 & 7.960 & 11.530 & 7.670 \\
\hline & $R^{2}$ & 0.817 & 0.820 & 0.844 & 0.838 \\
\hline & Radical offset & -0.022 & -0.027 & -0.023 & -0.073 \\
\hline & Radical slope & 1.155 & 1.144 & 1.144 & 1.285 \\
\hline \multirow{4}{*}{$\begin{array}{l}\text { Sentinel-2: S2B } \\
\text { MSIL1C_20180810T174859_ } \\
\text { N0206_R141_ } \\
\text { T13TDE_20180810T212348 } \\
\text { WorldView-3: 18AUG10180726- } \\
\text { M1BS-013107057010_01_P002 } \\
\text { (Longmont, Colo.) }\end{array}$} & Uncertainty (\%) & 9.340 & 11.230 & 18.640 & 8.332 \\
\hline & $R^{2}$ & 0.852 & 0.841 & 0.868 & 0.826 \\
\hline & Radical offset & -0.011 & -0.014 & -0.010 & -0.057 \\
\hline & Radical slope & 1.395 & 1.385 & 1.412 & 1.534 \\
\hline
\end{tabular}


Table 7. Top of Atmosphere reflectance comparison of WorldView-3 images against Sentinel-2 images.

[ID, identifier; SWIR, shortwave infrared; Colo., Colorado; \%, percent; $R^{2}$, coefficient of determination]

\begin{tabular}{llrr}
\hline \multicolumn{1}{c}{ Scene ID } & \multicolumn{1}{c}{ Statistics } & SWIR 3 & SWIR 7 \\
\hline Sentinel-2: S2B_- & Uncertainty (\%) & 13.450 & 17.840 \\
MSIL1C_20180810T174859_N0206_ & $R^{2}$ & 0.813 & 0.832 \\
R141_T13TDE_20180810T212348 & Radical offset & -0.032 & -0.033 \\
WorldView-3: & Radical slope & 1.539 & 1.502 \\
18AUG10180728- & & & \\
A1BS-013107058010_01_P001 & & & \\
(Longmont, Colo.) & & \\
\hline
\end{tabular}

Table 8. Spatial performance of WorldView-3.

[FWHM, full width at half maximum; MTF, modular transfer function; NIR, near infrared]

\begin{tabular}{lcc}
\hline \multicolumn{1}{c}{ Spatial analysis } & FWHM & MTF at Nyquist \\
\hline Band 2-Blue & 1.2 pixels & 0.179 \\
Band 3-Green & 1.2 pixels & 0.185 \\
Band 5-Red & 1.2 pixels & 0.180 \\
Band 7-NIR 1 & 1.7 pixels & 0.093 \\
\hline
\end{tabular}

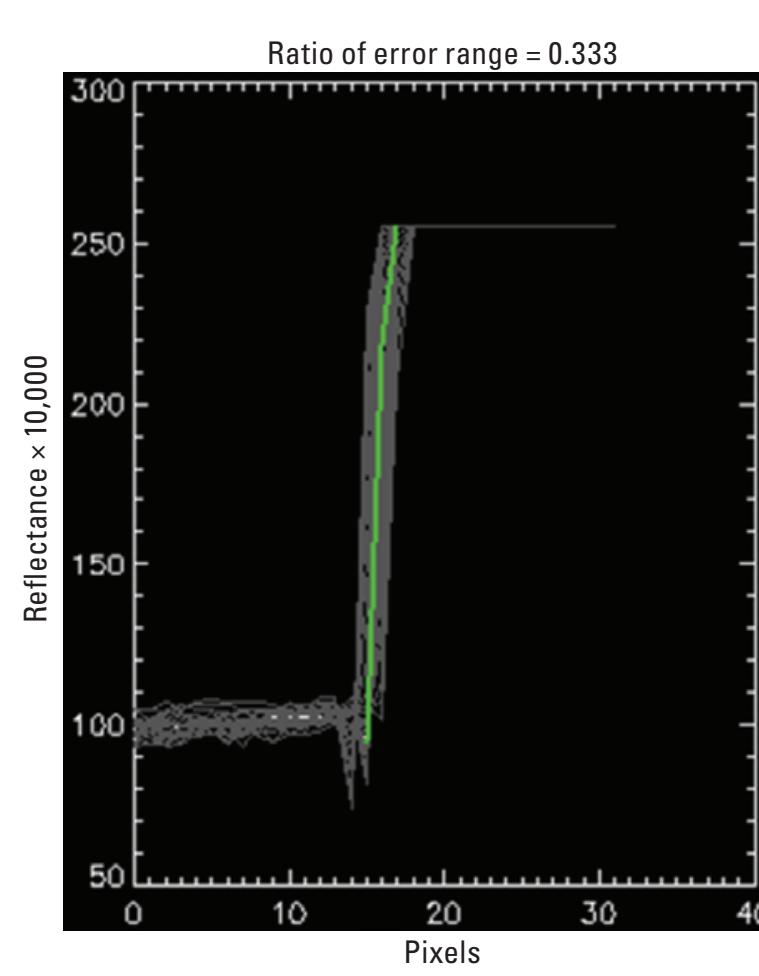

Full width at half maximum $=1.2$

Modulation transfer function at Nyquist $=0.1785$

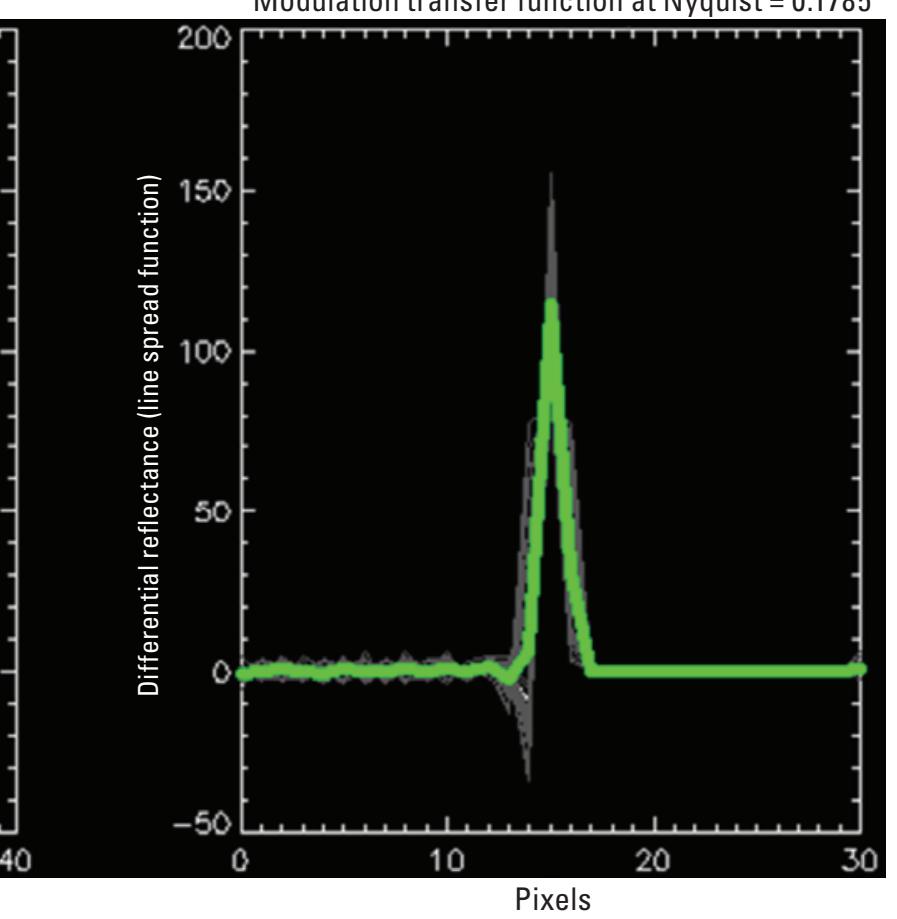

Figure 34. Band 2 (blue) edge spread and line spread functions. 
Ratio of error range $=0.333$

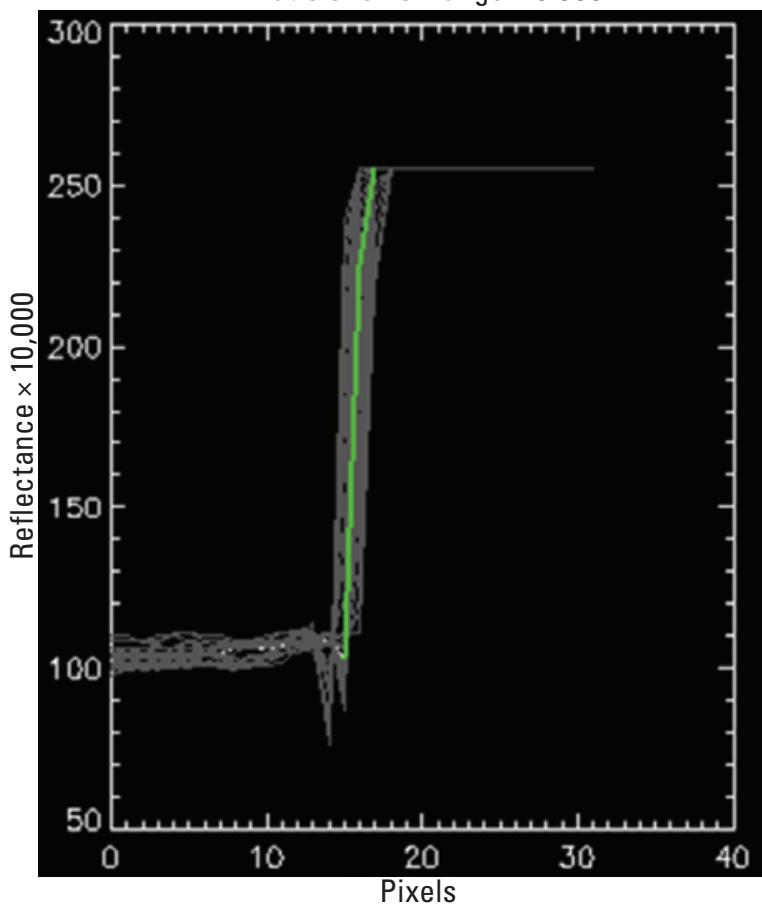

Full width at half maximum $=1.2$

Modulation transfer function at Nyquist $=0.1848$

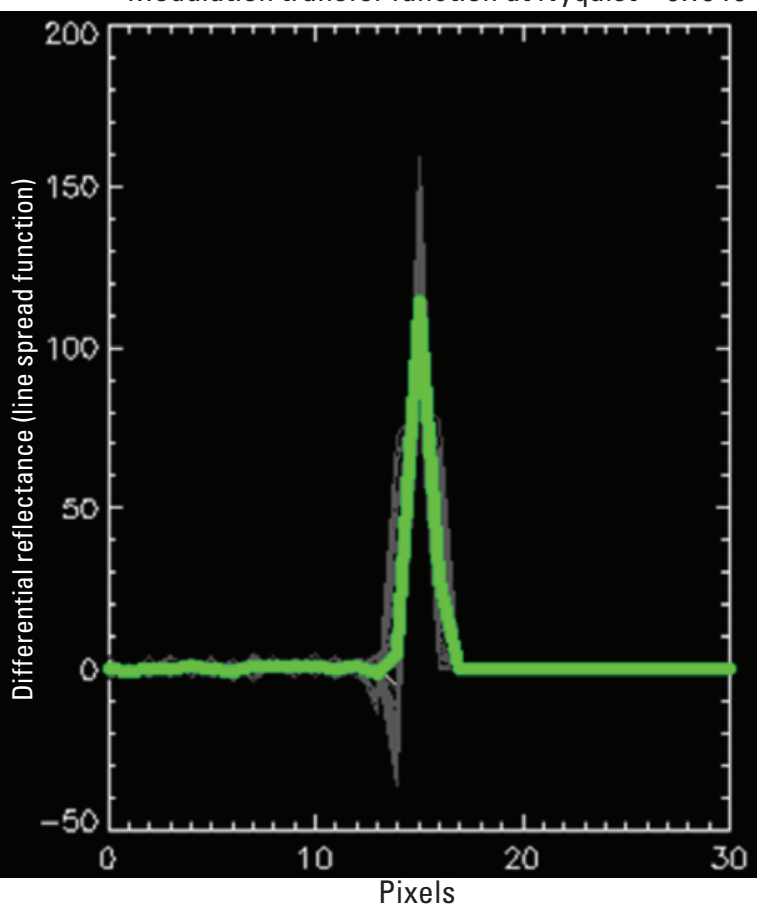

Figure 35. Band 3 (green) edge spread and line spread functions.

Ratio of error range $=0.324$

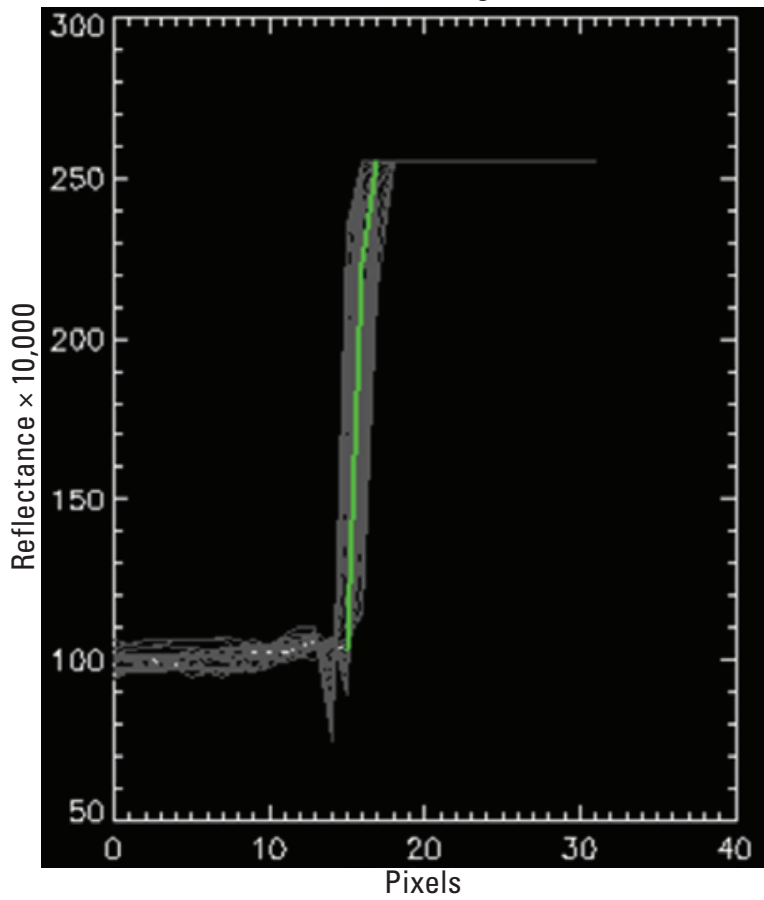

Full width at half maximum $=1.2$

Modulation transfer function at Nyquist $=0.1799$

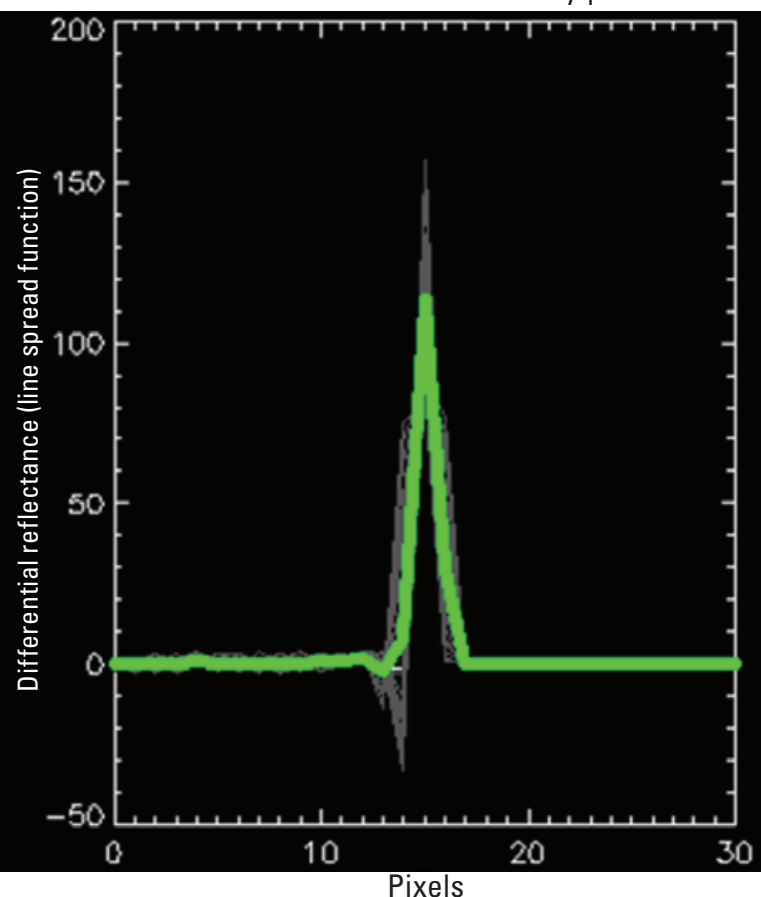

Figure 36. Band 5 (red) edge spread and line spread functions. 


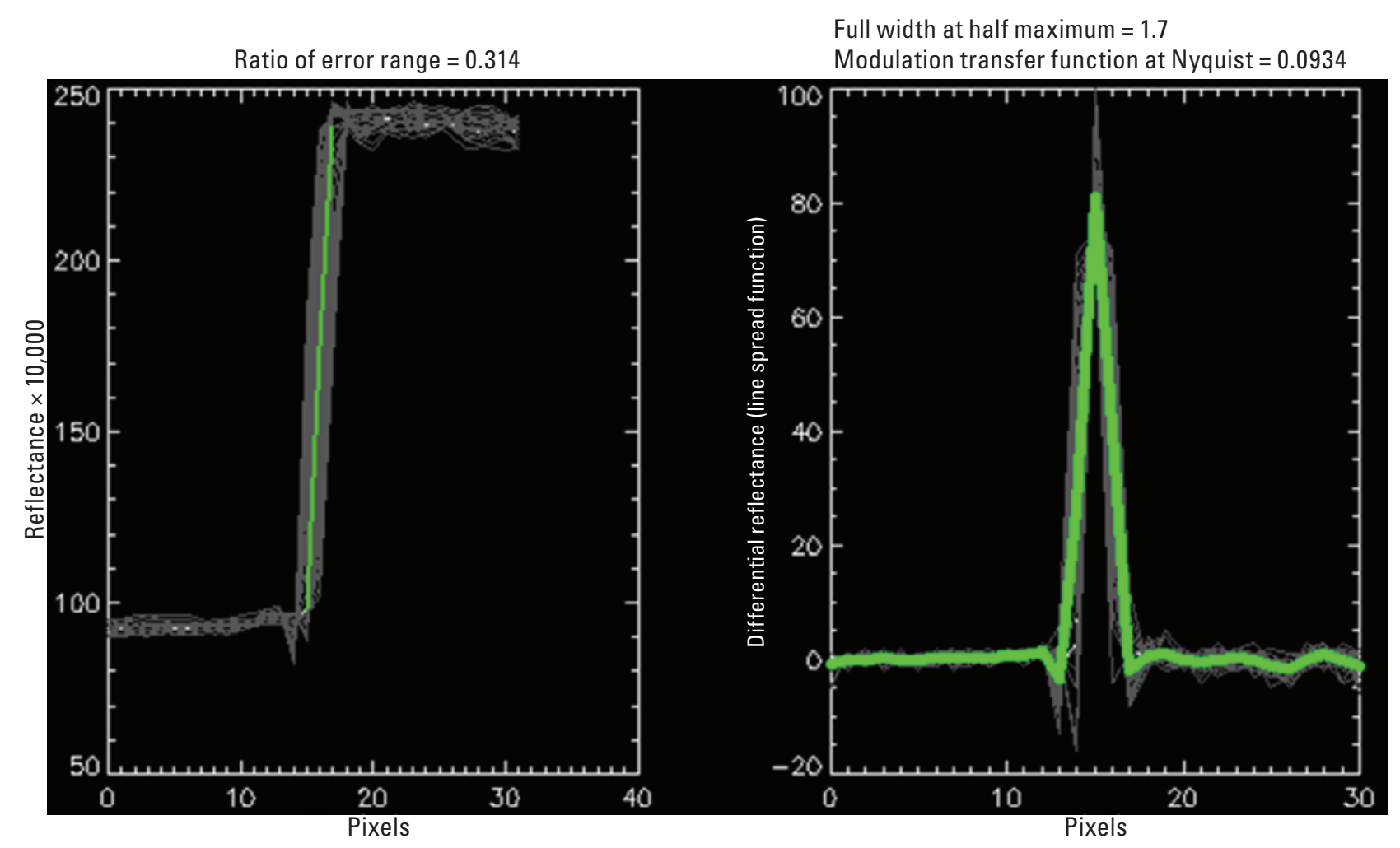

Figure 37. Band 7 (near infrared 1) edge spread and line spread functions.

\section{Summary and Conclusions}

This report summarizes the sensor performance of the Maxar WorldView-3 system based on the U.S. Geological Survey Earth Resources Observation and Science Cal/ Val Center of Excellence system characterization process. In summary, we have determined that this sensor provides an interior geometric performance of -0.09 ( -0.07 pixel) to 0.24 meter $(0.19$ pixel $)$, an exterior geometric performance of -21.10 ( -2.11 pixels) to 28.23 meters ( 2.82 pixels), a radiometric performance of -0.121 to 1.420 (offset and slope), and a spatial performance of 1.2 to 1.7 pixels at full width at half maximum, with a modulation transfer function at a Nyquist frequency of 0.093 to 0.185 .

In conclusion, we have completed an Earth Resources Observation and Science Cal/Val Center of Excellence standardized system characterization of the WorldView-3 sensing system. Although we follow characterization procedures that are standardized across the many sensors and sensing systems under evaluation, these procedures are customized to fit the individual sensor, as we have done with WorldView-3. The team has acquired the data, defined proper testing methodologies, carried out comparative tests against specific references, recorded measurements, completed data analyses, and quantified sensor performance accordingly. The team also endeavored to retain all data, measurements, and methods. This is key to ensure that all data and measurements are archived and accessible and that the performance results are reproducible.

The ECCOE project and associated Joint Agency Commercial Imagery Evaluation partners are always interested in reviewing sensor and remote sensing application assessments and would like to see and discuss information on similar data and product assessments and reviews. If you would like to discuss system characterization with the U.S. Geological Survey ECCOE and (or) the Joint Agency Commercial Imagery Evaluation team, please email us at eccoe@usgs.gov. 


\section{Selected References}

Ramaseri Chandra, S.N., Christopherson, J.B., and Casey, K.A., 2020, 2020 Joint Agency Commercial Imagery Evaluation-Remote sensing satellite compendium: U.S. Geological Survey Circular 1468 (ver. 1.1, October 2020), 253 p. [Also available at https://doi.org/10.3133/cir1468.] [Supersedes USGS Circular 1455.]

Satellite Imaging Corporation, 2017, WorldView-3 satellite sensor: Satellite Imaging Corporation web page, accessed October 2020 at https://www.satimagingcorp.com/satellitesensors/worldview-3.
U.S. Geological Survey, 2020a, EROS CalVal Center of Excellence (ECCOE): U.S. Geological Survey web page, accessed October 2020 at https://www.usgs.gov/corescience-systems/eros/calval/jacie?qt-science_support_page related_con=3\#qt-science_support_page_related_con.

U.S. Geological Survey, 2020b, Landsat missions-Glossary and acronyms: U.S. Geological Survey web page, accessed October 2020 at https://www.usgs.gov/core-sciencesystems/nli/landsat/glossary-and-acronyms. 

For more information about this publication, contact: Director, USGS Earth Resources Observation and Science Center 47914 252nd Street

Sioux Falls, SD 57198

605-594-6151

For additional information, visit: https://www.usgs.gov/centers/eros

Publishing support provided by the

Rolla Publishing Service Center 


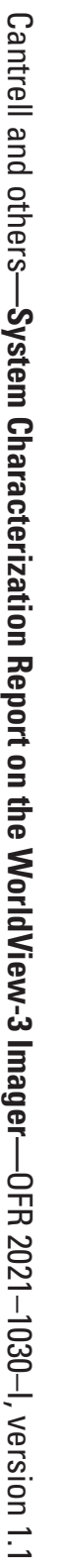

